\title{
Turbulent diffusivity in the free atmosphere inferred from MST radar measurements: a review
}

\author{
R. Wilson \\ Service d'Aéronomie/IPSL, Université P. et M. Curie, Paris, France \\ Received: 15 December 2003 - Revised: 16 June 2004 - Accepted: 24 June 2004 - Published: 29 November 2004 \\ Part of Special Issue "10th International Workshop on Technical and Scientific Aspects of MST Radar (MST10)"
}

\begin{abstract}
The actual impact on vertical transport of smallscale turbulence in the free atmosphere is still a debated issue. Numerous estimates of an eddy diffusivity exist, clearly showing a lack of consensus. MST radars were, and continue to be, very useful for studying atmospheric turbulence, as radar measurements allow one to estimate the dissipation rates of energy (kinetic and potential) associated with turbulent events. The two commonly used methods for estimating the dissipation rates, from the backscattered power and from the Doppler width, are discussed. The inference methods of a local diffusivity (local meaning here "within" the turbulent patch) by using the dissipation rates are reviewed, with some of the uncertainty causes being stressed. Climatological results of turbulence diffusivity inferred from radar measurements are reviewed and compared.

As revealed by high resolution MST radar measurements, atmospheric turbulence is intermittent in space and time. Recent theoretical works suggest that the effective diffusivity of such a patchy turbulence is related to statistical parameters describing the morphology of turbulent events: filling factor, lifetime and height of the patches. It thus appears that a statistical description of the turbulent patches' characteristics is required in order to evaluate and parameterize the actual impact of small-scale turbulence on transport of energy and materials. Clearly, MST radars could be an essential tool in that matter.
\end{abstract}

Key words. Meteorology and atmospheric dynamics (turbulence; instruments and technique) - Radio science (remote sensing)

\section{Introduction}

Small-scale turbulence is a very essential process of atmospheric and oceanic dynamic since (i) it is the sink for mechanical energy through dissipative processes, (ii) it induces

Correspondence to: R. Wilson

(richard.wilson@aero.jussieu.fr) drag on the large-scale flow through Reynolds stress, (iii) it induces irreversible transport of heat, mass and minor constituents. However, the actual impact of small-scale turbulence on the atmospheric dynamic - energy budget and vertical transport - is still an open issue. For instance, the question as to whether the small-scale turbulence has any significant impact on vertical transport in the upper-troposphere lower-stratosphere (UTLS), and in the mesosphere as well, is still debated.

Various evaluations of the turbulent diffusivity $K_{\theta}\left(\mathrm{m}^{2} / \mathrm{s}\right)$ for the UTLS and for the mesosphere are shown in Table 1. In this table are reported estimations of the diffusivity inferred either from indirect methods - by combining the observations of tracer profiles and a mathematical model for transport, production and losses - or from direct measurements of energetics parameters of turbulence, are reported. These estimations can hardly be directly compared however, as they have sometimes very different meanings.

Some of these evaluations are bulk transport coefficients, i.e. on a planetary scale. The vertical transport terms are evaluated by taking into account the production and loss processes on large space and time scales (several weeks) (Massie and Hunten, 1981; Ogawa and Shimazaki, 1975). However, the actual impact of small-scale turbulence cannot be directly retrieved from these values, as other non-turbulent processes might contribute to vertical transport as the (diabatic) Brewer-Dobson circulation.

A small impact on vertical transport in the lower stratosphere $\left(K_{\theta} \sim 0.01-0.02 \mathrm{~m}^{2} / \mathrm{s}\right.$ or less) was inferred from the in-situ observations of filamentary structures of tracers and by using a numerical model representing the stretching and mixing processes (Waugh, 1997; Balluch and Haynes, 1997). On the other hand, Legras et al. (2003), by combining observed ozone profiles and a stochastic-dynamical model for reconstructing the profiles, found a much more significant impact ( $K_{\theta} \approx 0.1 \mathrm{~m}^{2} / \mathrm{s}$ or larger).

Further difficulties arise when comparing the diffusivity estimates inferred from measurements. Some evaluations are local ones (i.e. within the turbulent patches), either 
Table 1. Various estimations of atmospheric diffusivity $\left(\mathrm{m}^{2} / \mathrm{s}\right)$ for the UTLS and mesosphere.

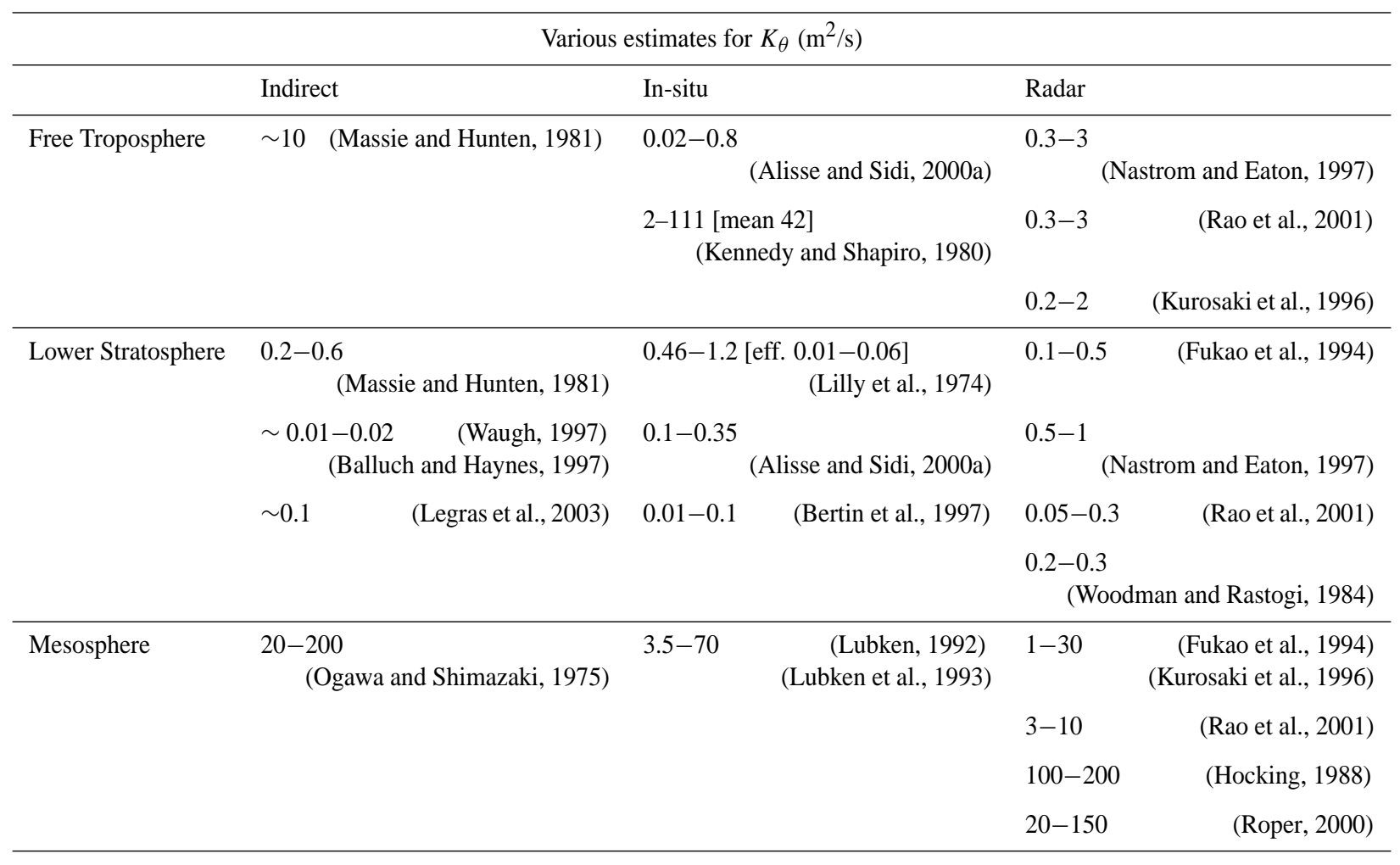

from in-situ measurements (e.g. Lilly et al., 1974; Barat and Bertin, 1984; Lubken, 1992; Alisse and Sidi, 2000a), or from radar measurements (e.g. Hocking, 1988; Fukao et al., 1994; Roper, 2000; Rao et al., 2001). Other estimates are inferred from an evaluation of the heat (or tracer) flux across a given height level, by using both local evaluations of turbulence strength and fractional time of turbulent events. These evaluations thus take into account, in some aspects, the space-time intermittency of turbulence (e.g. Lilly et al., 1974; Woodman and Rastogi, 1984) (the values between brackets are from Lilly et al. (1974) in the table). Furthermore, some estimates are Eulerian, as radar measurements (a fixed volume being sampled), others being performed quasi-instantaneously, either at a quasi-constant height level (instrumented aircrafts) or along a quasi-vertical profile (balloons or rockets borne instruments).

In fact, there exists a certain confusion in the literature when comparing these "turbulent diffusivities". One can, however, observe at this stage that, beyond the natural variability of turbulence strength, the dispersion of these "effective" diffusivity estimates (two to three orders of magnitude) reveals a lack of consensus about the actual impact of smallscale turbulence on transport processes (Table 1).

MST radars have the unique ability to allow for measurements related to the energetics of small-scale turbulence with a high space-time resolution, in the UTLS and in the mesosphere. The aim of this paper is to review and discuss the methods used in evaluating the turbulence diffusivity from MST radar measurements. In Sect. 2, the main characteristics of turbulence in the free atmosphere are described: length scales, energetics and related diffusivity. The inference of turbulent diffusivity from radar measurements is a two-step process. First, the turbulence strength is characterized, usually from the KE dissipation rate, $\epsilon_{k}$. Second, the turbulent diffusivity is evaluated by assuming a relationship between the dissipation rate $\epsilon_{k}$ and the heat flux (or buoyancy flux). The two commonly used methods for estimating $\epsilon_{k}$, from the structure constant $C_{n}^{2}$ or from the turbulent velocity variance $u^{2}$, are described in Sect. 3. We also introduce the equations describing the (unfamiliar) turbulent potential energy (balance equation, dissipation rate) and its relation to mixing. Indeed, as noticed by Hocking and $\mathrm{Mu}$ (1997); Hocking (1999), the structure constant $C_{n}^{2}$ is a quantity related to the potential energy of the turbulent flow. On the other hand, numerous authors showed that mixing events in a stratified flow lead to a change in the background potential energy through the dissipation of available potential energy (Dillon and Park, 1987; McIntyre, 1989; Winters et al., 1995). The estimation of a turbulent diffusivity from radar measurements relies on measured quantities $\left(\epsilon_{k}\right.$ or $\left.C_{n}^{2}\right)$ but also on non-measured parameters (i.e. local stratification, mixing efficiency, filling factor). that have to be evaluated independently. This point will be discussed in some detail in Sect. 4. Quantitative results are described in the following 


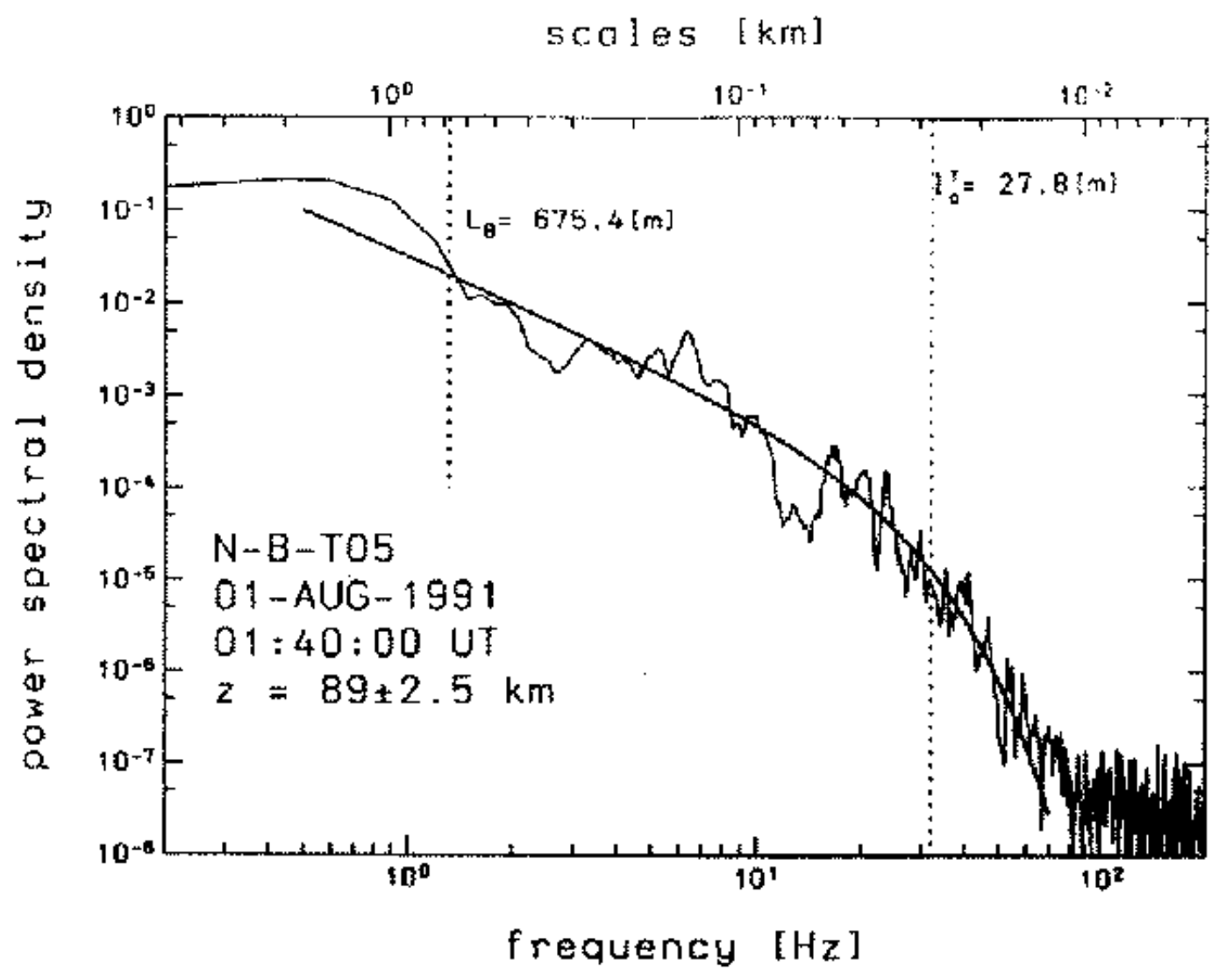

Fig. 1. Power spectrum of relative density fluctuations together with Tatarskii's (1971) theoretical model (from Lubken, 1992).

section. Climatological studies of turbulence diffusivity inferred from radar measurements are reviewed and discussed. Comparative studies of radar methods are also reviewed.

A key issue in evaluating the actual diffusive properties of small-scale turbulence in the atmosphere (and ocean as well) is the intermittency. In the last part of the paper, theoretical and semi-empirical works on the diffusive properties of a patchy turbulence are presented. A few suggestions for future radar studies will also be advanced.

\section{Inertial turbulence in a stratified atmosphere}

Turbulent motions in a stratified medium induce fluctuations of velocity but also of tracers, such as temperature, humidity, or refractive index. Numerous evidences of an inertial subrange "à la Kolmogorov" were observed "in-situ" in the free atmosphere from micro-structures measurements (e.g. Barat, 1984; Barat and Bertin, 1984; Sidi and Dalaudier, 1990; Lubken, 1992). The inertial turbulent subrange is characterized by a $-5 / 3$ spectral index for $1-D$ (observable) spectra of the velocity or tracers' fluctuations (Fig. 1, from Lubken, 1992).

It is important to note that the energy spectrum of air motions is also characterized by a $k^{-5 / 3}$-range ( $k$ being the horizontal wave number) in the mesoscale region, i.e. from wavelengths of some few $\mathrm{km}$ to wavelengths of about $500 \mathrm{~km}$
(Gage, 1979; Nastrom and Gage, 1985). There is still a debate about the interpretation of such a spectrum. Dewan (1979) and VanZandt (1982) explained the $k^{-5 / 3}$-range by a direct energy cascade of gravity waves (from large to small scales). On the other hand, Gage (1979) interpreted the $k^{-5 / 3}$-spectrum as the spectrum of 2-D turbulence with a negative energy flux (from small to large scales). In a recent paper, by considering the second and third order structure functions, Lindborg (1999) brought support to the first hypothesis (i.e. the wave hypothesis), at least for the $k^{5 / 3}$ range. In any event, such a $k^{-5 / 3}$-spectrum must not be interpreted as the spectrum of inertial turbulence, and cannot be used in order to infer small-scale turbulence parameters (TKE or dissipation rates).

\subsection{Turbulent scales}

A variety of turbulence scales were defined. Two important length scales are the outer scale $L_{m}$, characterizing the size of the largest turbulent eddies of the inertial range, and the inner scale $l_{o}$, a transition scale between the inertial and the viscous ranges. The outer scale (sometimes labelled the integral scale) is related to the rms wind velocity $u$ and TKE dissipation rate $\epsilon_{k}$ in the inertial range through (e.g. Tennekes and Lumley, 1972, p 20):

$L_{m} \sim u^{3} / \epsilon_{k}$. 


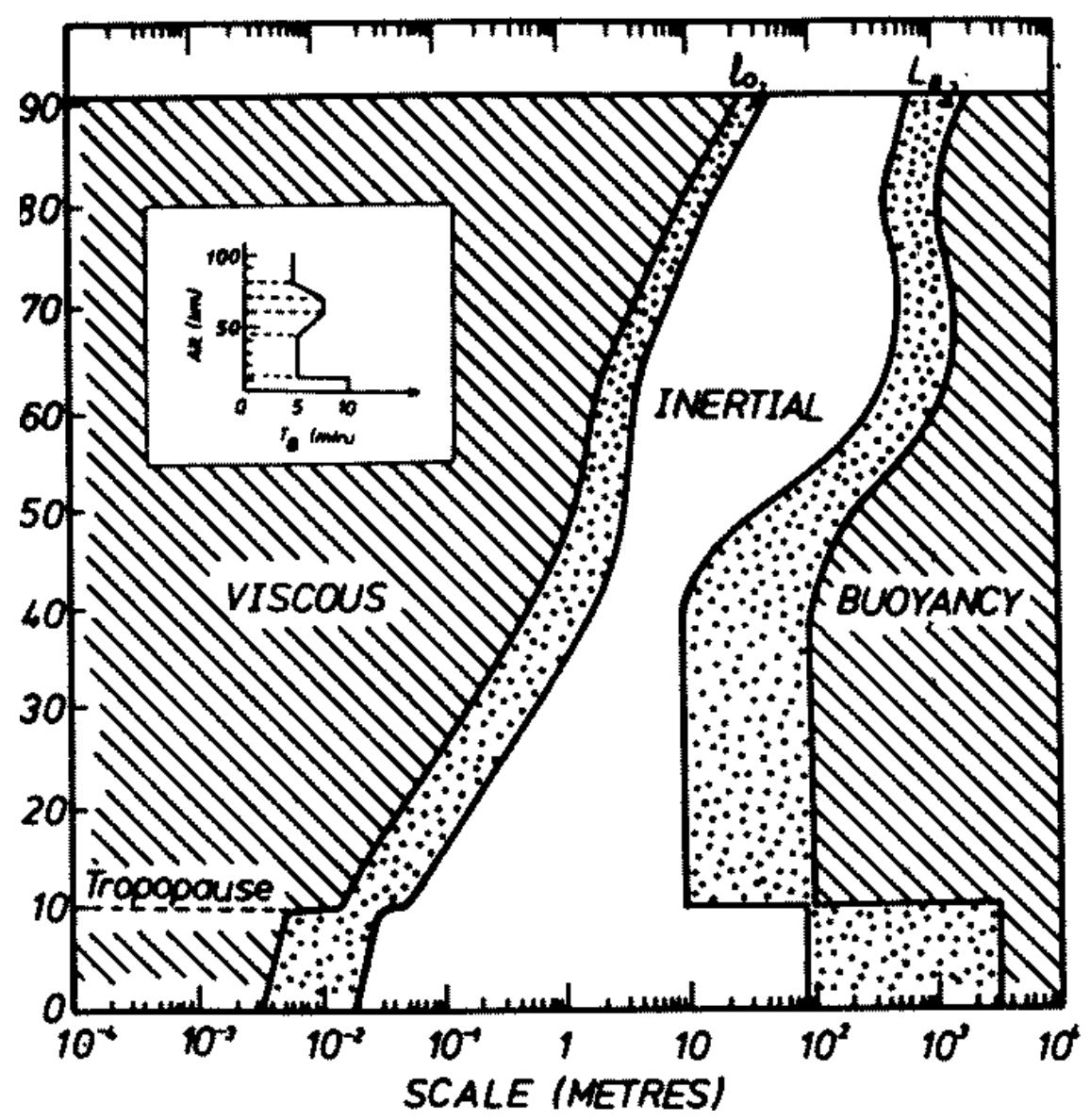

Fig. 2. Inner and outer scales of turbulence in the atmosphere (from Hocking, 1985).

A variety of expressions exists for the outer scale, however. A relevant scale for stratified turbulence is the buoyancy scale $L_{B}$, which represents the displacement of a fluid parcel converting all its vertical kinetic energy to potential energy:

$L_{B}=w / N$,

where $w$ is the rms vertical velocity and $N$ the buoyancy (or Brunt-Väisälä ) angular frequency $\left(\mathrm{s}^{-1}\right)$. The vertical scale $L_{B}$ is frequently expressed in a different form. By assuming $L_{m} \sim L_{B}$, and combining Eq. (2) and Eq. (1), the buoyancy scale reads (e.g. Fernando, 2002):

$L_{B} \sim\left(\frac{\epsilon_{k}}{N^{3}}\right)^{1 / 2} \equiv L_{O}$,

with $L_{O}$ being labelled the Ozmidov scale. Alternatively to the buoyancy scale Eq. (2), a shear scale is sometimes used as an outer scale (e.g. Tennekes and Lumley, 1972, pp. 48 and 62):

$L_{S}=\frac{u}{S}$,

where $S$ is the vertical shear of the horizontal mean velocity.

A commonly used expression for the outer scale was proposed by Weinstock (1978): $L_{B}=(2 \pi / C) L_{O}$, where $C$ is a dimensionless "constant". Weinstock (1978) first proposed $C=0.62$, and latter suggested that $C$ should not be treated as a constant (Weinstock, 1992). Others used turbulent length scales used are the Ellison scale $L_{E}$, and the Thorpe scales $L_{T}$-scales related to the rms vertical displacement (e.g. Smyth and Moum, 2000).

Concerning the inner scale (of temperature fluctuations), a widely accepted definition was proposed by Hill (1978):

$l_{o}=7.4\left(\frac{v^{3}}{\epsilon_{k}}\right)^{1 / 4}=7.4 l_{k}$,

where $v$ is the kinematic viscosity $\left(\mathrm{m}^{2} / \mathrm{s}\right), l_{k}$ being the Kolmogorov microscale. Due to the fact that the Prandtl number is not unity, the inner scale for velocity fluctuations is slightly different, i.e. $l_{o} \approx 12.8 l_{k}$.

For the atmosphere (Fig. 2, from Hocking 1985):

- the inner scale of the inertial subrange increases from $\sim 10^{-2} \mathrm{~m}$ in the free troposphere to $\sim 10 \mathrm{~m}$ in the upper mesosphere.

- the outer scale ranges from $10 \mathrm{~m}$ to about $1000 \mathrm{~m}$, with the smaller values being observed in the stable lower stratosphere, the larger ones in the troposphere and mesosphere. 
Evaluations of inner and outer scales in the UTLS (5-20 km) are reported in Eaton and Nastrom (1998). These scales are inferred from radar estimates of the TKE and related dissipation rate. Inner scale values were observed to increase from $1 \mathrm{~cm}$ at $5 \mathrm{~km}$ to about $8 \mathrm{~cm}$ at $20 \mathrm{~km}$ altitude. The outer scale (shear scale) is found to range from $\sim 10 \mathrm{~m}$ (lower stratosphere) to $\sim 65 \mathrm{~m}$ (free troposphere). By combining rocket and radar data, Watkins et al. (1988) observed an inner scale ranging from 2 to $6 \mathrm{~m}$ in the upper mesosphere ( 80 to $90 \mathrm{~km}$ height domain).

\subsection{Energetics}

Typically, energy (kinetic or potential) of turbulent motions ranges from $\sim 10^{-2} \mathrm{~J} / \mathrm{kg}$ in the lower stratosphere to about $1-10 \mathrm{~J} / \mathrm{kg}$ or so in the free troposphere and mesosphere (Fukao et al., 1994; Nastrom and Eaton, 1997; Alisse and Sidi, 2000a; Lubken, 1992; Hall et al., 1999). By noting that $\epsilon_{k} \sim u^{3} / L_{m}$ (Eq. 1) and assuming $L_{m} \sim L_{B}$ leads to:

$\epsilon_{k} \sim u^{2} N$.

The dissipation rate is thus $\sim 10^{-2} \times \mathrm{TKE}$, typically.

The turbulence intensity is usually characterized from the TKE per unit mass $(\mathrm{J} / \mathrm{Kg})$

$E_{K}=\frac{1}{2}\left(u^{2}+v^{2}+w^{2}\right)$,

where $u, v, w$ are the rms turbulent velocities. One important characteristic of stratified turbulence is that a fraction of TKE is converted into available turbulent potential energy (TPE)

$E_{P}=\frac{1}{2} N^{2} \zeta^{2}=\frac{1}{2} \frac{g^{2}}{N^{2}} \frac{\overline{\theta^{2}}}{\bar{\theta}^{2}}$,

where $\theta$ is the generalized potential temperature (Ottersten, $1969 b), \bar{\theta}$ being a reference state, $\zeta$ is the rms vertical displacement inferred from the potential temperature variance (i.e. the Ellison scale). It is precisely that fraction of energy which is related to the heat (and mass) transport. Indeed, Eq. (8) shows that the dissipation of temperature variance induces a dissipation of TPE (later discussed). In a stratified medium $(d \bar{\theta} / d z>0)$, the dissipation of (potential) temperature variance, in reducing the stratification, induces a downward heat flux.

The equation describing the time evolution of TKE in a stratified medium reads (Tennekes and Lumley, 1992, p. 63; Gill, 1982, pp. 76-78)

$\frac{d E_{K}}{d t}=P-B-\epsilon_{k}+\nabla \cdot \mathbf{F}_{\mathbf{K}}$,

where $\nabla \cdot \mathbf{F}_{\mathbf{K}}$ is a transport term through surface fluxes, $P$ is the production term through Reynolds stress acting in a shear, and $B$ is the buoyancy flux, expressing a reversible conversion of TKE into TPE,

$P=-\overline{u^{\prime} w^{\prime}} \frac{d \bar{u}}{d z} ; \quad B=-\frac{g}{\bar{\theta}} \overline{w^{\prime} \theta^{\prime}}$.
The time evolution of temperature variance reads, (Tennekes and Lumley, 1972, p. 95)

$\frac{1}{2} \frac{d \theta^{\prime 2}}{d t}=-\overline{w^{\prime} \theta^{\prime}} \frac{d \bar{\theta}}{d z}-\epsilon_{\theta}+\nabla \cdot \mathbf{F}_{\theta}$,

where $\epsilon_{\theta}$ is the dissipation rate of half temperature variance,with $\nabla \cdot \mathbf{F}_{\theta}$ being a transport term. By noting that the temperature variance is related to the TPE (Eq. 8), one obtains an equation for the time evolution of TPE by multiplying Eq. (11) by $(g / N \bar{\theta})^{2}$ :

$\frac{d E_{P}}{d t}=B-\epsilon_{p}+\nabla \cdot \mathbf{F}_{\mathbf{p}}$.

The buoyancy flux is here a source term for TPE, dissipated through thermal diffusivity $\left(\epsilon_{p} \propto \epsilon_{\theta}\right)$. Therefore, the dissipation rate of temperature variance, $\epsilon_{\theta}$, can be interpreted as a dissipation rate of available potential energy.

Two simplifying assumptions are typically made (likely due to the lack of alternative possibilities). By assuming spatial homogeneity, the divergence terms vanishes. By further assuming stationarity, the balance equations for TKE and TPE reduce to

$P-B=\epsilon_{k}$

$B=\epsilon_{p}$.

The production $P$ of TKE is balanced by the buoyancy flux $B$ (reversible conversion into TPE) and the dissipation $\epsilon_{k}$ (irreversible). The production term of TPE $B$ is simply balanced by the dissipation rate $\epsilon_{p}$.

\subsection{Turbulent diffusivity}

The diffusive properties of turbulence are commonly expressed from the heat flux $\Phi_{\theta}=\rho C_{p} \overline{w^{\prime} \theta^{\prime}}$ ( $\rho$ is atmospheric density, $C_{p}$ the specific heat at constant pressure). The eddy diffusion coefficient for heat is defined as $K_{\theta}=-\overline{w^{\prime} \theta^{\prime}} /(d \bar{\theta} / d z)$.

From Eq. (14) an indirect evaluation of the diffusivity can be estimated from the dissipation rate of temperature variance (Osborn and Cox, 1972)

$K_{\theta}=\frac{\epsilon_{\theta}}{(d \theta / d z)^{2}}$.

Equivalently, with the above notations, (multiplying the numerator and denominator of Eq. (15) by $\left.(g / N \bar{\theta})^{2}\right)$ one obtains:

$K_{\theta}=\frac{\epsilon_{p}}{N^{2}}$.

Another indirect evaluation, from the TKE dissipation rate, is inferred from Eq. (13) (Lilly et al., 1974; Osborn, 1980):

$K_{\theta}=\gamma \frac{\epsilon_{k}}{N^{2}}$,

where $\gamma$ is sometimes referred to as the mixing efficiency. Under the above hypotheses of homogeneity and stationarity, $\gamma$ reads

$\gamma=\frac{B}{P-B}=\frac{R_{f}}{1-R_{f}}=\frac{\epsilon_{p}}{\epsilon_{k}}$, 
where $R_{f}=B / P$ is the flux Richardson number. As noticed by several authors however, the efficiency of mixing should rather be defined as the fraction of the supplied energy that is actually used for mixing, that is $B / P=R_{f}$, rather than $\gamma$. We therefore chose to simply label $\gamma$ as the dissipation rates ratio.

\section{Radar measurements of the turbulence energetics}

Radar measurements related to small-scale turbulence are usually the reflectivity and the wind velocity variance. Under the hypothesis that the inhomogeneities of refractive index are due to homogeneous and stationary inertial turbulence, the reflectivity is a simple function of the structure constant $C_{n}^{2}$ Tatarskii (1961); Ottersten (1969a). $C_{n}^{2}$ can be interpreted as the mean squared-difference of refractive index for unity distance (i.e. the value of the structure function for one meter separation). The wind velocity variance relates to the TKE, provided that the non-turbulent contributions to that variance can be removed. A variety of radar techniques exist for estimating the wind velocity: from the line-of-sight velocity differences from meteors (Roper, 1966); from the imaging Doppler interferometry scattering positions (Roper and Brosnahan, 1997), from spaced antenna full correlation analysis (Briggs, 1980; Manson et al., 1981), and from the spectral broadening observed by MST Doppler radars. (Hocking, 1983). This last technique, applicable for narrow beams VHF and UHF radars, was widely used from the troposphere to the mesosphere. The other techniques, mostly based on MF radars measurements, were rather used in studying the mesospheric dynamics. A comparative discussion about these techniques is beyond the scope of this paper. However, some of the approximations and assumptions of the inference methods of turbulence parameters are independent of the measurement techniques.

In the following of this section, we shall mostly discuss the two commonly used measurement methods for turbulence studies from MST radars. Following the terminology of Cohn (1995), the method relying on the reflectivity $\eta$, or related $C_{n}^{2}$, to the dissipation rate $\epsilon_{k}$, will be labelled the "power method". The method relying on the Doppler width to $\epsilon_{k}$, will be also labelled the "spectral width method". New radar methods for estimating the dissipation rate $\epsilon_{k}$ will also be briefly mentioned. Again, the subject of this paper is not to review radar techniques used for turbulence measurements (some good articles exist, e.g. Hocking, 1985, 1997; Cohn, 1995; Hocking and $\mathrm{Mu}, 1997$ ) but rather to discuss the methods used to infer the turbulent diffusivity from radar measurements of reflectivity and wind velocity variance.

\subsection{The power method}

The power method relates the radar reflectivity to the structure constant of refractive index $C_{n}^{2}$ (VanZandt et al., 1978; Gage et al., 1980), by assuming that the reflecting layers are due to inertial and (locally) homogeneous turbulence.
In other words, the basic assumption of this method is that the scattering process is Bragg scattering due to isotropic refractive index inhomogeneities (Tatarskii, 1961). Supporting this hypothesis, a direct comparison between high resolution in-situ measurements of refractive index fluctuations and oblique radar backscattered power was successfully conducted by Luce et al. (1996). Of course, the power method requires a radar calibration. The power method can only be applied if other sources of (back)scattering can be neglected. Non-turbulent causes of radio waves scattering include Rayleigh scattering (from hydro-meteors or insects, involving UHF radars) and Fresnel scattering (partial reflection, involving VHF radars). By comparing high-resolution in-situ measurements and vertical power of a VHF radar, Luce et al. (1995) showed that partial reflection from temperature sheets, described by Dalaudier et al. (1994), is likely to be the main mechanism contributing to vertical echo enhancements.

The isotropic scatterers (i.e. isotropic refractive index inhomogeneities) are thought to be the dominant scattering process for zenith angles larger than $\sim 10-15^{\circ}$ (e.g. Tsuda et al., 1986; Hocking et al., 1990), although aspect sensitivity was observed in some cases for zenithal angles as large as $20^{\circ}$ (Tsuda et al., 1997a), and even $30^{\circ}$ (Worthington et al., 1999a,b). Aspect sensitivity has not been observed for UHF radars. Several authors also reported radar observations of an azimuthal anisotropy of the backscattered power of oblique beams (e.g. Tsuda et al., 1986; Hocking et al., 1990; Hooper and Thomas, 1995; Worthington and Thomas, 1997; Worthington et al., 1999b). Such an anisotropy of backscattered power is believed to be due to the tilting of aspect sensitive surfaces by gravity waves and vertical wind shears (Worthington and Thomas, 1997), i.e. it is not a turbulence induced effect. However, another hypothesis for the VHF zenithal aspect sensitivity relies on the turbulence anisotropy (e.g. Tsuda et al., 1997a). For a review on the aspect sensitivity of VHF radar echoes, see Luce et al. (2002b). In any event, such aspect sensitive scatterers may induce error (over-estimation) in evaluating the isotropic-turbulence intensity.

Within a stratified medium, the refractive index fluctuations $\delta n$ are induced by vertical displacement $\delta z$ (Tatarskii, 1961)

$\delta n=M \delta z$,

where $M$ is the gradient of generalized potential index for unionized atmosphere (Tatarskii, 1961; Ottersten, 1969b):

$$
M=-0.776 \times 10^{-6} \frac{P}{\bar{T}}\left[\left(1+15500 \frac{q}{\bar{T}}\right) \frac{N^{2}}{g}-\frac{15500}{2 \bar{T}} \frac{\partial q}{\partial z}\right],
$$

where $P$ is the pressure $(\mathrm{Pa}), T$ the temperature $(\mathrm{K}), q$ the specific humidity $(\mathrm{g} / \mathrm{g})$. If humidity can be neglected, as it is the case in the stratosphere, $M$ depends on the static stability only:

$M=-0.776 \times 10^{-6} \frac{P}{\bar{T}} \frac{N^{2}}{g}$. 
Note that, in the mesosphere, $M$ also depends on the electron density.

Vertical displacements inducing a conversion into (available) TPE (Eq. 8), and noting that $\left(\overline{\delta z^{2}}\right)^{1 / 2} \approx \zeta$, one can express $E_{P}$ as a function of the variance of refractive index fluctuations $\overline{\delta n^{2}}$ :

$$
E_{P}=\frac{1}{2} N^{2} \zeta^{2}=\frac{1}{2}\left(\frac{N}{M}\right)^{2} \overline{\delta n^{2}} .
$$

The dissipation of refractive index variance $\left(\epsilon_{n}\right)$ can thus be expressed as a function of the dissipation rate of TPE $\left(\epsilon_{p}\right)$. From Eq. (22):

$\epsilon_{p}=\left(\frac{N}{M}\right)^{2} \epsilon_{n}$

Under the assumption of isotropic inertial turbulence, the 3D spectrum of refractive index fluctuations is proportional to the structure constant $C_{n}^{2}$ (Tatarskii, 1961, pp. 46-58), that is:

$C_{n}^{2}=a^{2} \frac{\epsilon_{n}}{\epsilon_{k}^{1 / 3}}$.

As a function of the TPE dissipation rate Eq. (23), the structure function reads:

$C_{n}^{2}=a^{2}\left(\frac{M}{N}\right)^{2} \frac{\epsilon_{p}}{\epsilon_{k}^{1 / 3}}$.

Hence, the structure constant $C_{n}^{2}$ is related to both the dissipation rates of TPE and TKE. One can therefore express $C_{n}^{2}$ either as a function of $\epsilon_{k}$ (e.g. VanZandt et al., 1978; Hocking, 1999):

$C_{n}^{2}=\gamma a^{2}\left(\frac{M}{N}\right)^{2} \epsilon_{k}^{2 / 3}$

or as a function of $\epsilon_{p}$ (Dole et al., 2001)

$C_{n}^{2}=\gamma^{1 / 3} a^{2}\left(\frac{M}{N}\right)^{2} \epsilon_{p}^{2 / 3}$.

As noticed by numerous authors (e.g. VanZandt et al., 1978; Gage et al., 1980), a further complication comes from the fact that the radar reflectivity $\eta$, and thus the inferred $C_{n}^{2}$, are weighted volume averages $\left(<\eta>{ }_{v o l}\right.$ and $\left\langle C_{n}^{2}>{ }_{v o l}\right)$ (a uniform reflectivity within the sampling radar volume is assumed):

$$
<C_{n}^{2}>_{\text {vol }}=F_{T} C_{n}^{2},
$$

where $F_{T}$ is the turbulent fraction of the sampled volume. Therefore, the local dissipation rates (within the turbulent layer) must be expressed as a function of the volume averaged $<C_{n}^{2}>{ }_{v o l}$;

$\epsilon_{k}=\frac{1}{\gamma^{3 / 2}}\left(\frac{1}{a^{2}} \frac{N^{2}}{M^{2}} \frac{<C_{n}^{2}>_{v o l}}{F_{T}}\right)^{3 / 2}$ $\epsilon_{p}=\frac{1}{\gamma^{1 / 2}}\left(\frac{1}{a^{2}} \frac{N^{2}}{M^{2}} \frac{<C_{n}^{2}>_{v o l}}{F_{T}}\right)^{3 / 2}$.

The inferred dissipation rates only differ by the power of the $\gamma$ term. The $\epsilon_{p}$ estimate is rather more robust, showing a weaker dependency on the unknown $\gamma$ term, than the $\epsilon_{k}$ estimate (Dole and Wilson, 2000). Indeed, the refractive index fluctuations are rather related to potential energy (depending on vertical motions and stratification) than to kinetic energy. Notice, however that these two expressions for the dissipation rates (Eqs. 29 and 30) lead to an equivalent turbulent diffusivity $K_{\theta}$ (Eqs. 16 and 17).

\subsection{The spectral width method}

Turbulent motions induce a widening of the velocity distribution and thus a spectral broadening of the backscattered echo. But other non-turbulent processes also contribute to the spectral broadening (e.g. Hocking, 1985; Gossard and Strauch, 1983; Nastrom and Eaton, 1997):

- beam and shear broadening, related to the beam geometry;

- wave or 2-D turbulence contamination.

The non-turbulent effects must be removed. With the various causes of broadening being independent of each other, the induced variances simply add, i.e.:

$\sigma_{o b s}^{2}=\sigma_{T}^{2}+\sigma_{B+S}^{2}+\sigma_{W}^{2}$,

where $\sigma_{o b s}$ is the observed spectral width (half power-half width in $\mathrm{Hz}), \sigma_{T}$ being the turbulent contribution to that broadening. Beam and shear broadening $\sigma_{B+S}$ have to be evaluated from the known wind velocity profile, taking into account the beam geometry. Nastrom and Eaton (1997), Chu (2002), and VanZandt et al. (2002) presented formulae that accounts for the background wind speed across a radar beam. The wave (or 2-D turbulence) $\sigma_{W}$ can be reduced a by short integration time (e.g. Cohn, 1995), or by using a wave model (Hocking, 1988; Nastrom and Eaton, 1997).

The rms turbulent velocity relates to $\sigma_{T}$ as $u=\left(\lambda_{r} / 2\right) \sigma_{T} / \sqrt{(2 \ln 2)}$. Nastrom and Eaton (1997) observed that, for the narrow beam WSMR radar $\left(2.9^{\circ}\right.$ one way $3 \mathrm{~dB}$ beamwidth), the beam broadening is generally the largest correction term by far (WSMR stands for White Sand Missile Range). Figure 3, from Nastrom and Eaton (1997), shows mean profiles of the observed spectral width, compared to the applied corrections (total correction and the different terms).

A new radar technique for removing these non-turbulent (deterministic) effects has been recently proposed by VanZandt et al. (2002). The basic idea is to evaluate the broadening with two different beamwidths, the correction terms being approximately proportional to the beamwidth squared. The two beamwidth method has the advantage of being less sensitive than the standard single-beamwidth 


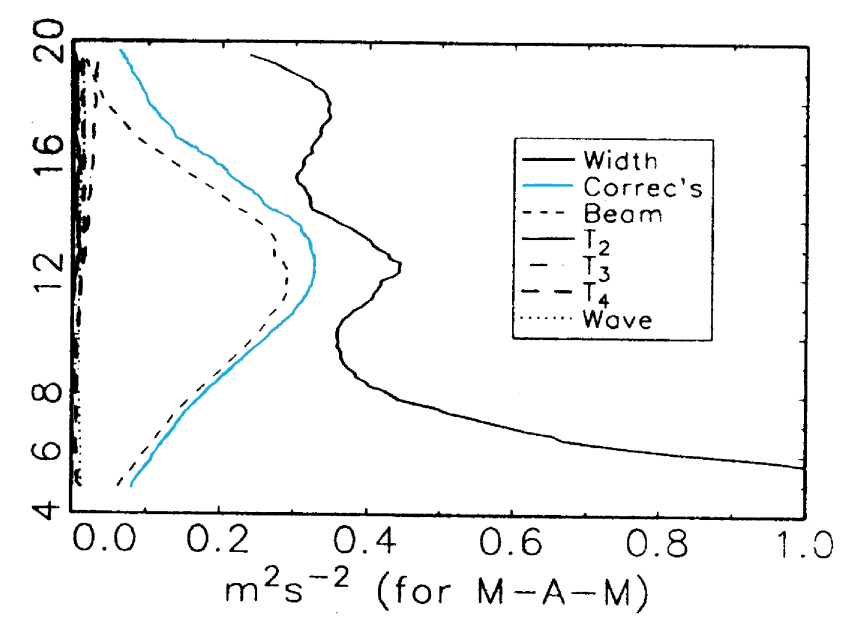

Fig. 3. Mean vertical profiles of the observed width with the corrections due to beam broadening, shear broadening and gravity-wave effects from Nastrom and Eaton (1997).

method to the necessary instrumental corrections of the observed spectral width $\sigma_{o b s}$.

Nastrom and Tsuda (2001) observed significant differences between the spectral widths from beams in two orthogonal planes - zonal and meridional - at both the MU (Middle and Upper atmosphere) radar and the WSMR radar. Such an anisotropy may be an effect due to the horizontal wind direction relative to the antenna beams (Chu, 2002).

The spectral width method has several advantages over the power method. First, there is no need for an absolute calibration of the radar. Second, the radar estimate of the velocity variance is a reflectivity and range weighted average (Doviak and Zrnić, 1993, pp. 109-110), i.e. the non-turbulent (nonreflecting) regions of the sampled volume do not contribute. The variance estimate is thus a weighted average on turbulent patches only. On the other hand, the turbulent velocity variance is related to the TKE dissipation rate. Consequently, there is no need for further information about the turbulent fraction or the dissipation ratio $\gamma$, in order to retrieve $\epsilon_{k}$. If concerned with mixing, however, (i.e. vertical transport of heat or mass) the turbulent diffusivity is only indirectly related to the TKE dissipation rate (through the energy conversion rate $B$ or the dissipation rates ratio $\gamma$ ).

Two methods were proposed (discussed by Hocking, 1999) in order to relate the measured $u^{2}$ to $\epsilon_{k}$.

- If the radar volume is filled with homogeneous turbulence, the observed variance results from the convolution of the velocity fluctuation field with the weighted sampling volume. By assuming a Kolmogorov spectrum, as well as a Gaussian shaped sampling volume, the dissipation rate reads (Frisch and Clifford, 1974; Gossard and Strauch, 1983):

$$
\epsilon_{k}=\frac{1}{\delta}\left[\frac{\overline{u^{2}}}{1.35 \alpha\left[1-\beta^{2} / 15\right]}\right]^{3 / 2},
$$

$$
\text { where }\left\{\begin{array}{l}
\delta=\sigma_{b} ; \beta^{2} \approx 1-\left(\sigma_{r} / \sigma_{b}\right)^{2} \quad \text { if } \sigma_{r}<\sigma_{b} \\
\delta=\sigma_{r} ; \beta^{2} \approx 4\left(1-\left(\sigma_{b} / \sigma_{r}\right)^{2}\right) \text { if } \sigma_{b}<\sigma_{r}
\end{array} .\right.
$$

- If the outer scale of turbulence is smaller than any scale of the sampled volume, the relationship between the variance (i.e. TKE) and the dissipation rate is rather dependent on the outer scale $L_{m}$ (Sato and Woodman, 1982; Hocking, 1983). Weinstock (1978) suggested that this outer scale is likely proportional to the Ozmidov scale $L_{O}$

$$
L_{m} \approx 3 \pi L_{O} \sim 3 \pi\left(\frac{\epsilon}{N^{3}}\right)^{1 / 2} .
$$

Therefore

$$
\epsilon_{k} \approx 0.47 u^{2} N \text {. }
$$

This last relationship is widely used in most MST radars studies of atmospheric turbulence. Notice, however, that the relation between $L_{m}$ and $L_{O}$ (Eq. 33) has been questioned by Weinstock (1992), as it seems to lead to too high a value for the dissipation rates ratio.

A variant of the spectral width method, sometimes labelled as the "variance method", is based on the direct estimation of the wind velocity variance from the velocity spectrum (e.g. Hall et al., 2000; Satheesan and Murthy, 2002). These authors assumed that motions are turbulent for short time fluctuations, in order to estimate $\epsilon_{k}$ from Eq. (34). However, some caution must be taken in this case as a $-5 / 3$ spectral index is not undoubtedly the signature of inertial turbulence. Satheesan and Murthy (2002) presented a comparative study of methods for retrieving the dissipation rate $\epsilon_{k}$ (to be discussed later).

\subsection{Direct estimation of $\epsilon_{k}$ : the two-wavelengths method}

A new radar technique was recently proposed by VanZandt et al. (2000), allowing for a direct estimations of the TKE dissipation rate. These authors used the ratio of simultaneous observations of radar reflectivity for two wavelengths close to the viscous scale, together with Hill's model of refractivity fluctuations due to turbulence (Hill, 1978; Frehlich, 1992). When neglecting scattering from particulates, the radar reflectivity $\eta(\lambda)\left(\mathrm{m}^{2} / \mathrm{m}^{2}\right)$ reads

$\eta(\lambda)=0.38 \frac{C_{n}^{2}}{\lambda^{1 / 3}} H\left(\lambda, \epsilon_{k}\right)$,

where the $H\left(\lambda, \epsilon_{k}\right)$ term takes into account the departure from the standard Kolmogorov model for the temperature fluctuations for scales close to the dissipation scale. With this dual-wavelengths technique most non-turbulent echoes are identified and filtered out.

\section{Stratification and unknown parameters}

Detailed knowledge of the local atmospheric conditions is needed for the correct interpretation of radar observations 
(Eqs. 29 or 34 for instance). Furthermore, the relationships between diffusion and energy dissipation rates rely on stratification (Eqs. 16 and 17). Depending on the method used, several additional parameters have to be evaluated: buoyancy frequency $N$ and gradient of generalized refractive index $M$, turbulent fraction $F_{T}$, as well as the dissipation rates ratio $\gamma$. Various methods or strategies have been proposed.

\subsection{Local atmospheric conditions}

The local stratification (within the radar sample volume) is described by $N$ and $M$. Both parameters are needed for relating $C_{n}^{2}$ to the dissipation rates (power method, Eqs. 29 and 30). The buoyancy frequency is also used in relating the TKE to $\epsilon_{k}$ (spectral width method, Eq. 34). Furthermore, the turbulent diffusivity $K_{\theta}$ is related to the dissipation rates through $N^{2}$ (Eqs. 16 and 17).

In the upper troposphere and lower stratosphere the specific humidity is negligible; $M$ depends mainly on the buoyancy frequency $N$. In most cases, the local $N$ is evaluated from additional in-situ measurements - usually from standard meteorological soundings. However, as observed by Dalaudier et al. (2001), the use of in-situ soundings does not allow for valuable estimations of the local stratification (within the radar volume) - at least for vertical resolutions of $\sim 150 \mathrm{~m}$ - likely because of the large variability of $N$ on relatively small time-and-space scales. The most probable explanation for such a rapid time and space evolution of the stability profile is the propagation of gravity waves. A good estimator - in the sense of the mathematical expectation of a random variable - remains likely the bulk buoyancy frequency, obtained either from a model (climatological or numerical), or from standard meteorological soundings with a low vertical resolution.

In the troposphere $M$ depends on both the Brunt-Väisälä frequency and humidity gradient $d q / d z$ (Eq. 20). In this case, the humidity gradient must necessarily be estimated from additional measurements. New data processing methods for retrieving the humidity profile by combining the radar reflectivity with additional measurements were recently proposed: with RASS (Radio Acoustic Sounding System) (Tsuda et al., 2001), GPS (Global Positioning System) (Gossard et al., 1998), or balloon-borne instruments (Mohan et al., 2001; Wilson and Dalaudier, 2003). Clearly, such combinations of instruments are very promising for future turbulence studies.

\subsection{The turbulent fraction}

The turbulent fraction, $F_{T}$, must be evaluated in order to retrieve the local $C_{n}^{2}$ from the volume-averaged $\left\langle C_{n}^{2}>\right.$ vol. On the other hand, as will be further discussed in Sect. 6, a statistical description of turbulent events (layers depths, lifetime, filling factor, intensity) is required for estimating the effective diffusivity of a patchy turbulence (Hocking and Röttger, 2001).
In-situ measurements - from instrumented aircrafts - in the lower stratosphere suggest $0.02<F_{T}<0.05$ (Lilly et al., 1974). From six balloon soundings of temperature and wind microstructures, Alisse and Sidi (2000a) observed $F_{T} \approx 0.18$ in the UTLS. High resolution radar measurements in the lower stratosphere indicate $0.1<F_{T}<0.2$ ((Dole et al., 2001). One difficulty in comparing these values comes from the fact that these instruments have different detection thresholds, implying different biases in the $F_{T}$ estimations (they are lower bounds) (see, for instance, Wilson and Dalaudier, 2003).

A turbulent fraction parameterization based on a simple statistical model for wind shears (i.e. a Gaussian distribution whose parameters are based on observed quantities) and by using an instability $R i$ criterion $\left(R i=N^{2} / S^{2}\right.$ is the gradient Richardson number) gives typically $0.015<F_{T}<0.5$ in the free troposphere, and $F_{T} \sim 0.03$ in the lower stratosphere (VanZandt et al., 1978). A simplified and somewhat ad hoc model was suggested by Gage et al. (1980): $F_{T}^{1 / 3} N^{2}=$ const. On the other hand, Weinstock (1981) made the assumption that the depth of a turbulent layer $L_{l}$ for developed turbulence is approximately equal to the outer scale $L_{m}$ (defining $\left.L_{m}=3 \pi L_{O}\right)$. By further assuming that there is only one turbulent layer within the sampled volume, that is $F_{t} \sim L_{l} / \Delta r$, the local $\epsilon_{k}$ reads:

$\epsilon_{k}=N^{2}\left(\frac{1}{a^{2} \gamma} \frac{C_{n}^{2} \Delta r}{3 \pi M^{2}}\right)^{6 / 7}$.

Although interesting, the hypothesis of a close relation between $L_{l}$ and $L_{O}$ has not been confirmed by high-resolution in-situ observations (Barat and Bertin, 1984; Alisse et al., 2000b), no clear relation being observed between the layer depth $L_{l}$ and the Ozmidov scale $L_{O}$.

\subsection{The dissipation rates ratio}

The $\gamma$ term appears - more or less explicitly - when relating the TKE dissipation rate $\epsilon_{k}$ (usually estimated) to the temperature variance (or TPE) dissipation rate. Hence, the expressions relating $C_{n}^{2}$ to the dissipation rates rates depends on $\gamma$ (Eqs. 26-27), as well as the relation between the heat flux and the TKE dissipation rates $\epsilon_{k}$ (Eq. 17). Indeed, $\gamma$ appears when expressing a conversion of TKE into TPE. Such a conversion rate is quantified by the flux Richardson number $R_{f}$. If homogeneity and stationarity are assumed, $R_{f}$ and $\gamma$ are very closely related since $R_{f}=\gamma /(1+\gamma)$ (Eq. 18).

A variety of expressions for $\gamma$ can be found in the literature (see Hocking, 1999, for a detailed review). For instance by writing $R_{f}=R i / P_{r}^{T}$ (where $R i$ is the gradient Richardson number, $P_{r}^{T}$ the turbulent Prandtl number), $\gamma$ reads:

$$
\gamma=\frac{1}{P_{r}^{T}} \frac{R i}{P_{r}^{T}-R i} \text {. }
$$

A "canonical" $R_{f}=0.25$ gives $\gamma=1 / 3$ (Lilly et al., 1974, based on Thorpe (1973) experiments). Under the hypothesis of a constant ratio of scales $\left(L_{m} / L_{O}\right) \approx 3 \pi$, Weinstock 


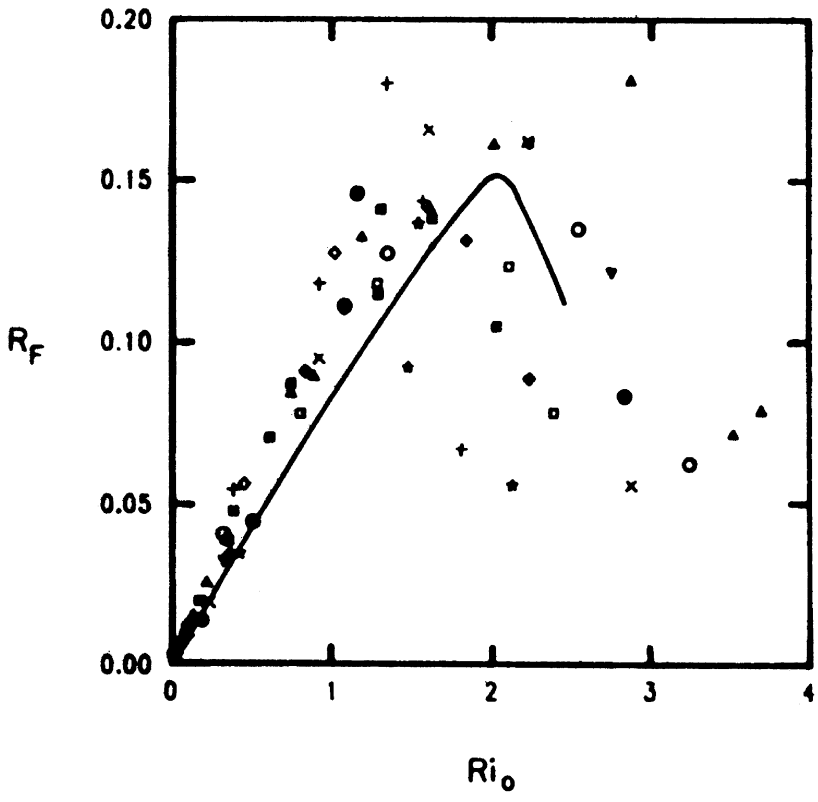

Fig. 4. The flux Richardson Number, $R_{f}$, versus the turbulent Richardson number, $R i_{o}=N^{2} L_{m}^{2} / q^{2}$ (observations and model), from Rohr et al. (1984) and Weinstock (1992).

(1978) suggests $\gamma \approx 0.8$. However, an accumulation of observational evidences suggest that $\gamma$ is likely to be smaller than 0.8 on the average (e.g. Weinstock, 1992). In fact, $\gamma$ is observed to be significantly variable. Several estimations in the oceanic thermocline, lakes, or laboratory experiments (water tank) indicate $0.1<\gamma<0.4$ (e.g. McEwan, 1983; Rohr et al., 1984; Gargett and Moum, 1995; Moum, 1996). In-situ and radar estimations in the UTLS indicate $0.06<\gamma<0.3$ (Alisse and Sidi, 2000a; Dole et al., 2001).

Laboratory experiments (e.g. Rohr and Van Atta, 1987; Ivey and Imberger, 1991), direct numerical simulations (e.g. Smyth et al., 2001) or theoretical considerations (Weinstock, 1992), suggest that $R_{f}$ (and thus $\gamma$ ) evolves during the life cycle of the turbulence event. It is usually observed that $R_{f}$ is decreasing with decreasing $R i_{0}$, the turbulent Richardson number $\left(R i_{0}=N^{2} L_{m}^{2} / q^{2}\right.$ expresses the ratio of TPE to TKE). Weinstock (1992), giving up the hypothesis of a constant ratio of scales $\left(L_{m} / L_{O}\right)$, suggests that $\gamma$ is a simple function of $R i_{0}$ (Fig. 4):

$\gamma \approx 1.2 R i_{0} \quad\left(\right.$ for $\left.R i_{0} \leq 2\right)$

Furthermore, experimental evidences (Fig. 5) suggest that the probability density function (PDF) of the dissipation rates ratio $\gamma$, inferred from the observed frequency of occurrence, is approximately log-normal (Dole et al., 2001). The likely value observed by these authors is about 0.1 , substantially smaller than $1 / 3$, as usually assumed.
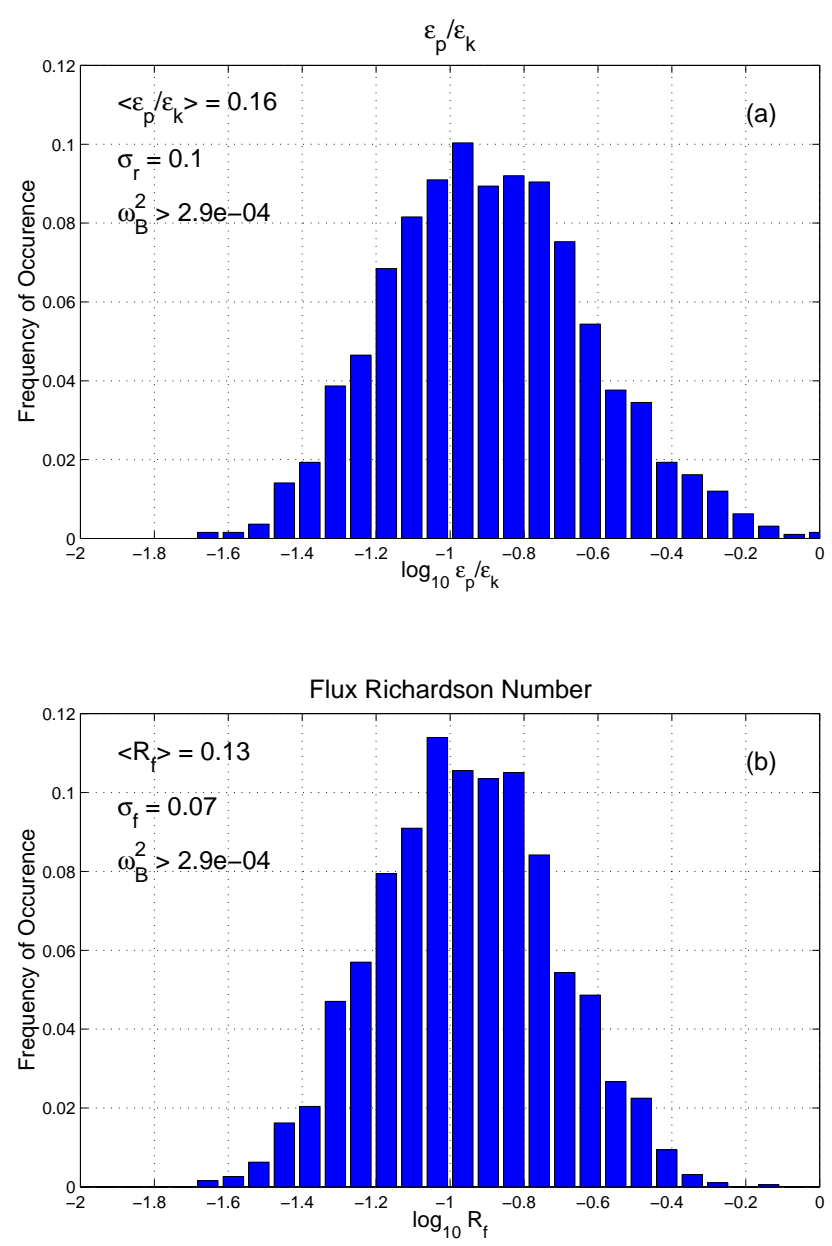

Fig. 5. The frequency of occurrence of the ratio of dissipation rates (a) and the inferred flux Richardson number (b). From Dole et al. (2001).

\section{Turbulent diffusivity inferred from MST radar mea- surements}

\subsection{Climatological results}

Several climatologies of turbulent diffusivity inferred from MST radar measurements were published, all of these based on the spectral width method (Hocking, 1988; Fukao et al., 1994; Kurosaki et al., 1996; Nastrom and Eaton, 1997; Rao et al., 2001). Vertical profiles of seasonal medians of $K_{\theta}$ for the troposphere and lower stratosphere are shown in Figs. 6 and 7. By comparing these profiles, the striking feature is the close agreement in the lower stratosphere, as well as the clear difference in the troposphere: either increasing with altitude over Shigaraki (Fukao et al., 1994; Kurosaki et al., 1996) of decreasing with altitude over WSMR (Nastrom and Eaton, 1997) and Gadanki (Rao et al., 2001). Such a difference has yet to be explained. The median values of the turbulent diffusivity in the UTLS is observed to range from $10^{-1}$ to $1 \mathrm{~m}^{2} / \mathrm{s}$, typically. An annual cycle for $K_{\theta}$ is observed in the UTLS, with the annual maxima being found to occur during winter 


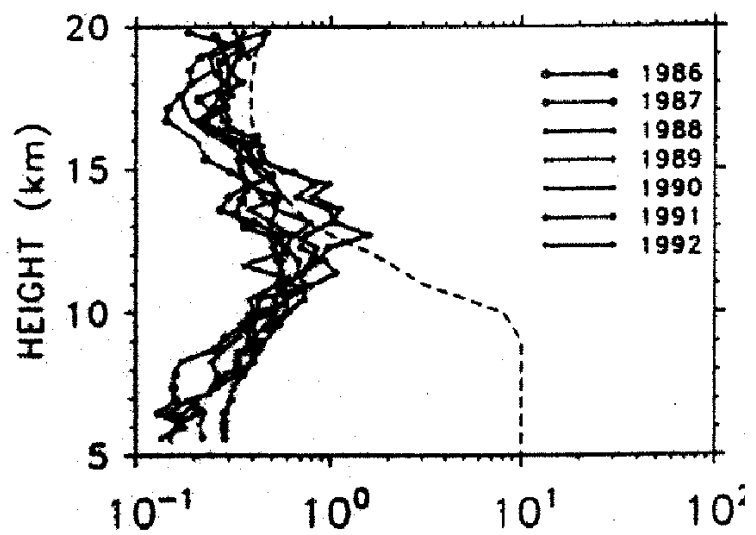

(a)

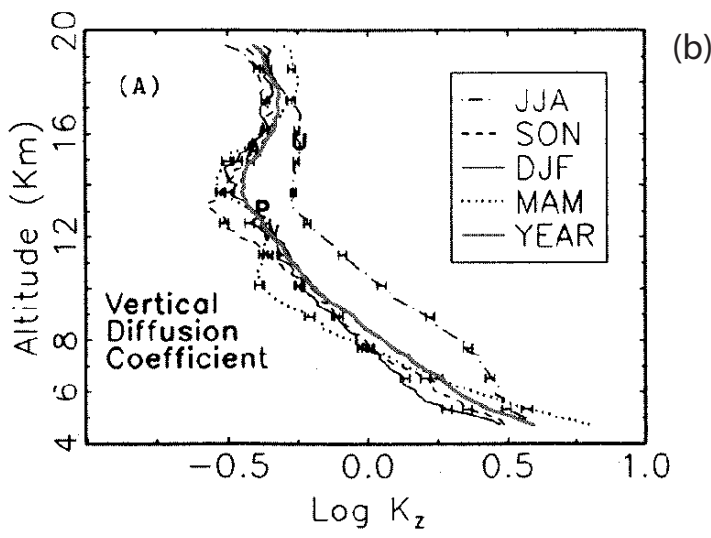

Fig. 6. (a): Annual median of $K_{\theta}$ inferred from the MU radar observations from 1986 to 1992 (Kurosaki et al., 1996). The dotted curve shows the diffusivity profile from Massie and Hunten (1981). (b): Seasonal medians of $\log K_{\theta}$ from the WSMR radar observations (Nastrom and Eaton, 1997).

over Shigaraki, during summer at WSMR, and during the monsoon and post-monsoon months at Gadanki.

$K_{\theta}$ is found to be generally larger in the mesosphere, ranging from $\sim 1$ to some $10^{2} \mathrm{~m}^{2} / \mathrm{s}$, typically. In the upper mesosphere - for altitudes ranging from 84 to $92 \mathrm{~km}$ - Hocking (1988) does not observe any clear annual cycle (from MF radar measurements). Fukao et al. (1994) and Kurosaki et al. (1996) observed a semiannual variation reaching one order of magnitude with solstice maxima in the middle mesosphere (around $\sim 75 \mathrm{~km}$ ). Rao et al. (2001) found a maximum of diffusivity around about $75 \mathrm{~km}$, with the annual maximum being observed during summer. These authors noticed that the observed variabilities of $K_{\theta}$ in the UTLS and in the mesosphere as well, are coincident with those of the gravity wave activity in the considered height range (e.g. Tsuda et al., 1990).

Also interesting is the observation that the PDF of local TKE dissipation rates in the upper stratosphere and lower stratosphere is approximately log-normal (Nastrom and Eaton, 1997; Dole et al., 2001). It seems reasonable to assume that the distribution of the related local diffusivities is also approximately log-normal.

Several authors have reported the existence of persistent layers of enhanced radar reflectivity (e.g. Nastrom and Eaton, 2001; Luce et al., 2002a). Intense turbulence in the lower stratosphere was also observed from in-situ measurements (Pavelin et al., 2002; Luce et al., 2002a). Such events are likely to be associated with strong mixing: $\left(K_{\theta} \geq 1 \mathrm{~m}^{2} / \mathrm{s}\right.$ in the lower stratosphere). Indeed, Luce et al. (2002a) observed that strong radar echo enhancements are associated with nearly neutralized layers. A climatological study of those enhanced reflectivity layers (Nastrom and Eaton, 2001) indicate that they are observed from 1 to $2 \%$ of the time, and that $25 \%$ of them last over $17 \mathrm{~h}$. The actual impact on vertical transport of such intense events has yet to be evaluated. The fact that these intense events are rather frequent (relative to a normal distribution of the reflectivities) is also a signature of intermittency.

\subsection{Comparative studies of inference methods}

Cohn (1995) compared two independent methods for estimating the dissipation rate $\epsilon_{k}$, the spectral width and the power methods, applied to the same data set. This author observed rather similar profiles in both the magnitude and shape, though differences are also found, likely due to the uncertainties on some parameters $\left(M^{2}, N^{2}, F_{T}, \gamma\right)$.

Satheesan and Murthy (2002) compared the power, the spectral width, and the variance methods for estimating the dissipation rate $\epsilon_{k}$. The obtained estimates for $\epsilon_{k}$ from the power method were generally lower than that from the other methods. They found that $\epsilon_{k}$ from the variance and spectral width methods agree quite well under low background wind conditions, whereas under high background wind conditions, $\epsilon_{k}$ from the width methods seems to be underestimated.

By using very high-resolution $(30 \mathrm{~m})$ radar measurements, Delage et al. (1997) performed an experimental comparison of diffusivities obtained by three independent methods: power method (29), spectral width method (34) and by assuming complete mixing within the turbulent layer (Eqs. 40-41), to be introduced in the next section. They found a reasonably good agreement between the various diffusivity estimates for turbulent layers whose thickness does not exceed $300 \mathrm{~m}$. For the thicker layers, the complete mixing assumption seems to lead to overestimated local diffusivities.

\subsection{Comparisons of radar and in-situ diffusivity estimates}

The turbulent diffusivities inferred from radar measurements compare rather well with in-situ estimations. For instance, Alisse et al. (2000b), by analyzing 36 turbulent layers observed in-situ from microstructure measurements of velocity and temperature, found $3 \times 10^{-3}<K_{\theta}<0.36 \mathrm{~m}^{2} / \mathrm{s}$ with a median of $\sim 0.1 \mathrm{~m}^{2} / \mathrm{s}$. By comparing various estimators for the eddy diffusivity within a single turbulent patch in the lower stratosphere, Bertin et al. (1997) found $10^{-3}<K_{\theta}<0.1 \mathrm{~m}^{2} / \mathrm{s}$. In the upper mesosphere Lubken $(1992,1997)$, from high 

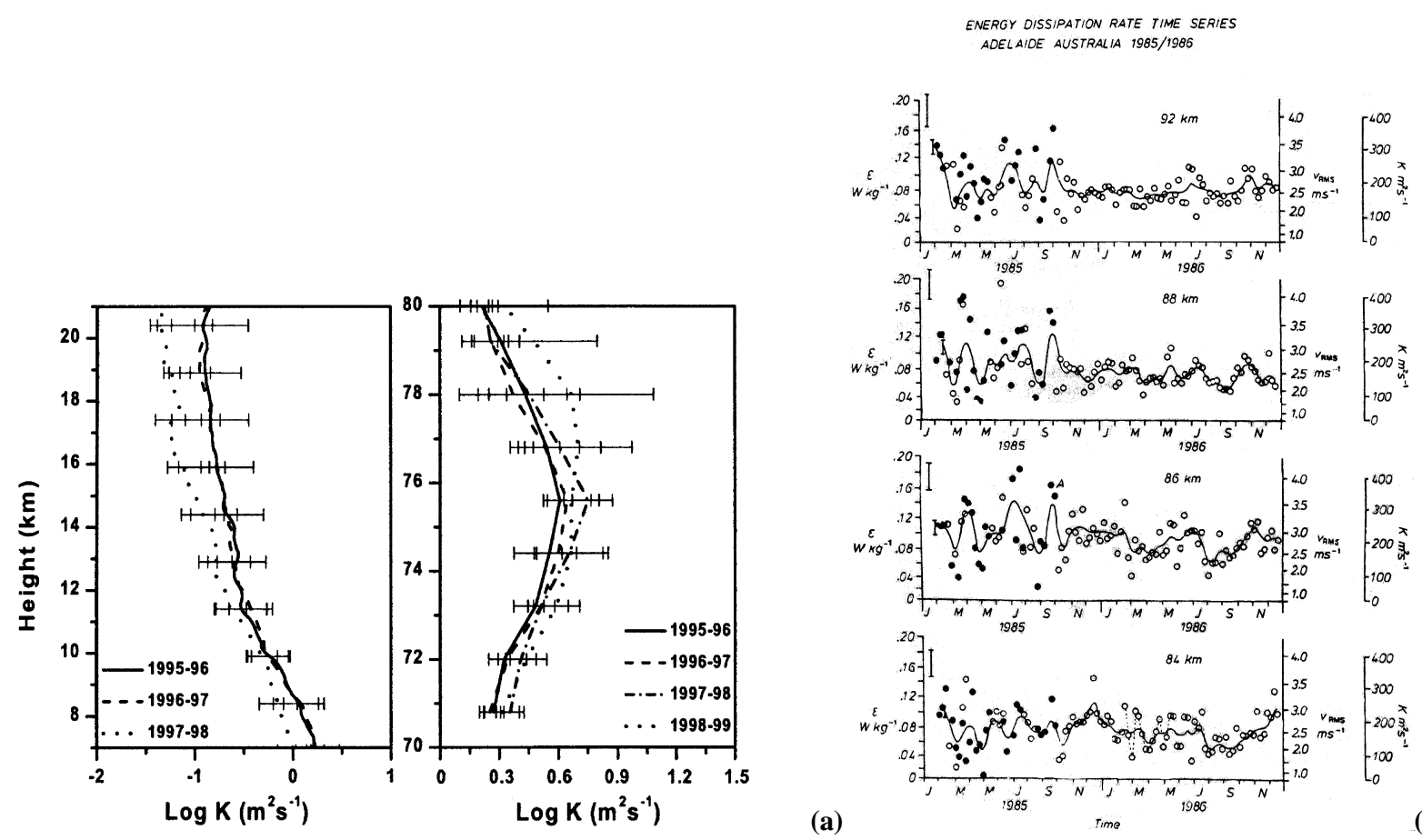

(b)

Fig. 7. (a): Annual medians of $\mathrm{K}\left(\mathrm{m}^{2} / \mathrm{s}\right)$ inferred from the Indian MST radar (Rao et al., 2001). (b): One week average of TKE dissipation rates (left axis), rms velocities and turbulent diffusivities (right axis), as a function of time for altitude 84, 86, 88 and $92 \mathrm{~km}$, during two years (1985-1986) (Hocking, 1988).

resolution in-situ density measurements, observed turbulent diffusivities ranging from 3 to $100 \mathrm{~m}^{2} / \mathrm{s}$. All these values compare very well with radar estimates of the local turbulent diffusivity, in the lower stratosphere and mesosphere as well (Figs. 6 and 7).

\section{Theoretical approaches}

Let us recall that the turbulent diffusivities (or related heat and mass fluxes) inferred from dissipation rates, are local estimates, that is within the turbulent patches. Now, the turbulence is observed to be intermittent in space and time, perhaps the most obvious feature revealed by MST radars about atmospheric turbulence (e.g. Czechowsky et al., 1979; Sato and Woodman, 1982; Woodman and Rastogi, 1984; Dole et al., 2001). An issue, considered in this section, is to infer from these local estimates, the actual (or effective) diffusivity, either within the sample volume (presumably not filled with homogeneous turbulence) or for larger spatial scales.

Several theoretical and semiempirical works enlighten the diffusive properties of intermittent turbulence. These works, in many aspects, give indications for future research.

\subsection{Diffusivity of patchy turbulence}

Radar observations showed that turbulent events occur within thin layers or patches (e.g. Sato and Woodman, 1982). The vertical scale of these layers ranges typically from a few hundred to about one thousand meters in the troposphere and mesosphere (e.g. Lubken et al., 1993), and from about ten meters to a few hundred meters in the stratosphere (e.g. Barat and Bertin, 1984; Alisse and Sidi, 2000a). The typical time scale is a few Brunt-Väisälä periods, say half an hour, or so. As already mentioned, however, some intense and persistent turbulent events are sometimes observed (Nastrom and Eaton, 2001).

The key issue now is to express an effective diffusivity by combining local flux estimates (i.e. within the turbulent patches) and parameters describing the morphology of the patches. In other words, how does one quantify the vertical transport - i.e. irreversible cross-isentropic transport - over scales much larger than the patch thickness? To enlighten this process, one can consider that the vertical displacement of a considered air parcel results from the encounters with turbulent patches, at random time, and with a random duration. Vertical diffusion can be seen as a continuous-time random walk process. The quantification of the effective diffusivity of such a patchy turbulence was addressed by Garrett (1979); Dewan (1981); Woodman and Rastogi (1984); Vaneste and Haynes (2000); Alisse et al. (2000b), among others.

By analogy with molecular diffusion, a vertical transport process can formally be considered as diffusive if the mean squared displacement of an air parcel $\sigma^{2}$ increases linearly with time $\Delta t$ (Taylor, 1921):

$\sigma^{2}=2 K \Delta t$, 

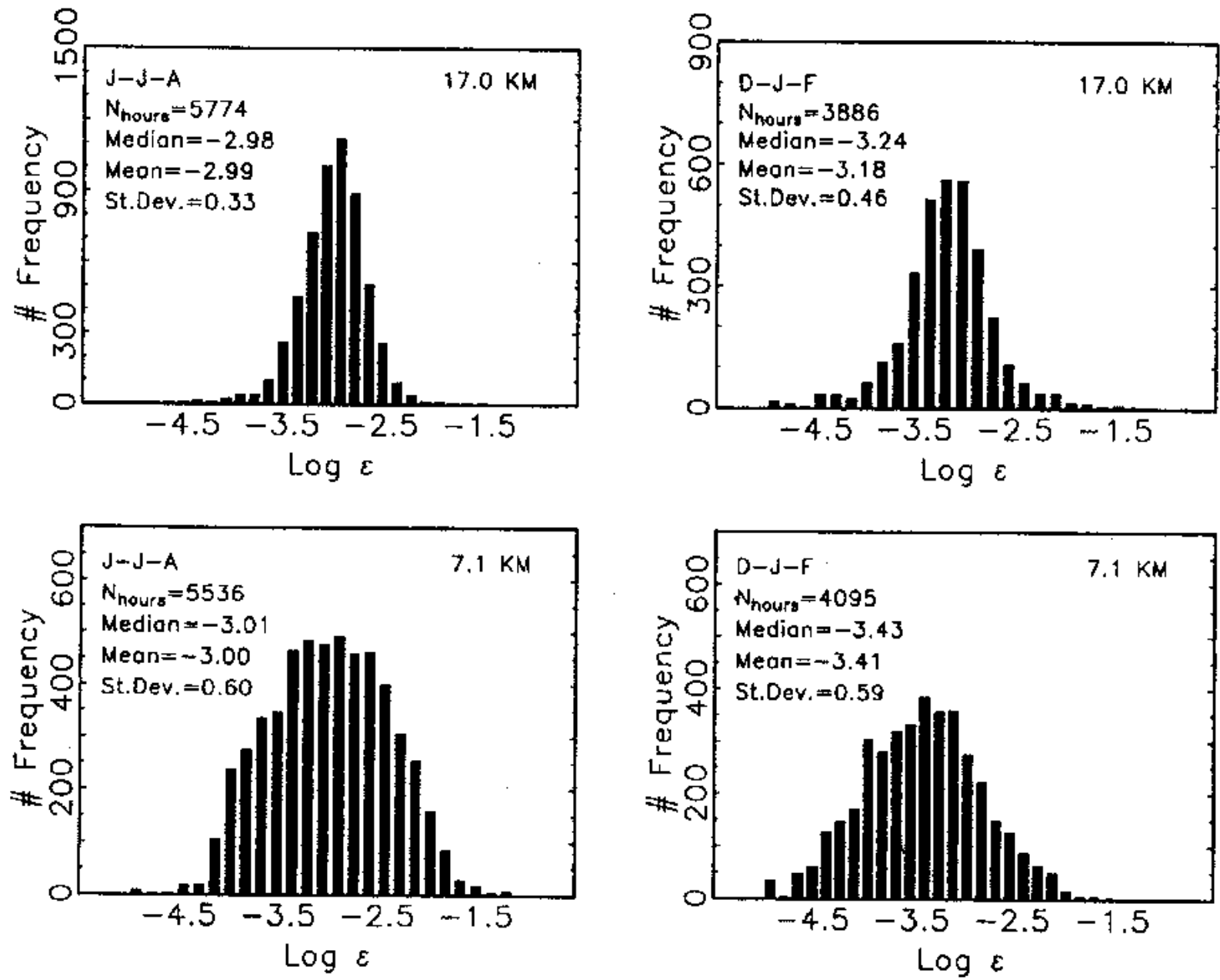

Fig. 8. Frequency distribution of $\log (\epsilon)$ during summer and winter seasons at 7.1 and $17 \mathrm{~km}$ altitude (Nastrom and Eaton, 1997).

where $K$, the proportionality factor, is the diffusion coefficient of the considered process. In a pioneering work, Dewan (1981) addressed the following question: can patchy turbulence be considered - and modeled - as an actual diffusive process? With a simple numerical model, Dewan simulated the dispersion of a tracer for randomly distributed mixing layers for various initial conditions. He assumed complete mixing within the mixing layers. The resulting distributions were compared with known analytical solutions. Dewan concluded that random mixing can be considered as a diffusive process in the long-time limit. For instance, Fig. 9 shows the concentration of a tracer as a function of space and time, resulting from the mixing of randomly distributed layers, for an initial $\delta$ function. Dewan (1981) proposed the following expression for the effective turbulent diffusivity:

$K_{\theta}^{e f f}=F_{T} \frac{\overline{d^{2}}}{8 \tau_{m}}$,

where $\overline{d^{2}}$ is the second moment of the mixing layers depths, $\tau_{m}$ being the mean time between successive mixing events. In an unpublished report, Dewan (1979) gave support to the use of expression (39) rather than a simpler expression, such as $K_{\theta}^{e f f}=F_{T} \overline{K_{\theta}^{\text {Patch }}}$ ( $K_{\theta}^{\text {Patch }}$ being the local diffusivity), arguing that complete mixing likely occurs within turbulent layers.

An estimation of an effective diffusivity based on a local flux evaluation was proposed by Woodman and Rastogi (1984). Considering an arbitrary level $z$ within a turbulent patch, the flux of a tracer is evaluated across that level by assuming complete mixing (Fig. 10). The local diffusivity (within the patch) is then a function of the layer thickness $d$ and of the lifetime of the patch $\tau_{L}$;

$K_{\theta}^{\text {Patch }}=\frac{d^{2}}{12 \tau_{L}}$.

An extension of the previous case is also considered: the layer sweeps an altitude range $D$ during their lifetime $\tau_{L}$ :

$K_{\theta}^{\text {Patch }}=\frac{d^{2}}{2 \tau_{L}}\left(R+\frac{1}{2} e^{-R}-\frac{1}{3}\right) \frac{1}{1+R}$,

where $R P=<D>/<d>$. By combining radar observations of the turbulent layers with these local estimates of diffusivity, these authors obtained a diffusivity profile for the UTLS 


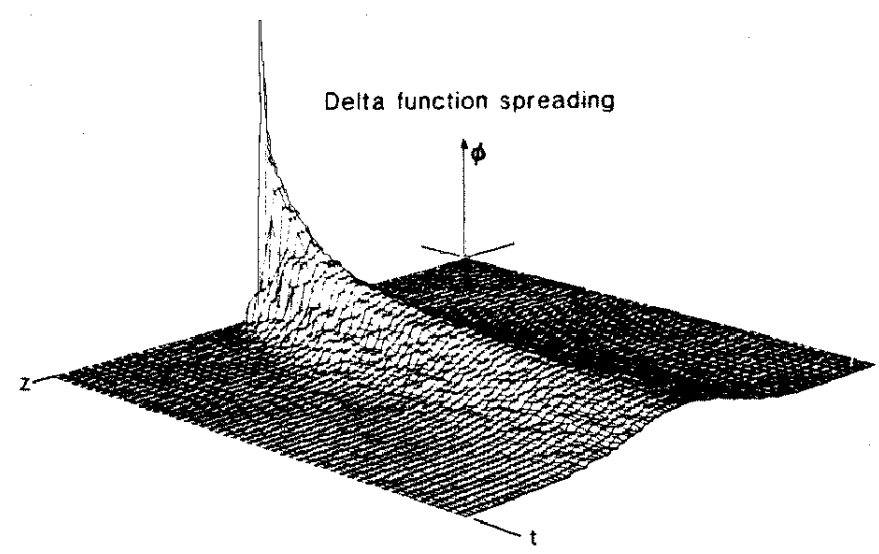

Fig. 9. Development of $\phi$ (concentration) as a function of time resulting in random mixing layers. The initial $\phi$ is a $\delta$ function. Complete mixing is assumed within the mixing layers (Dewan, 1981).

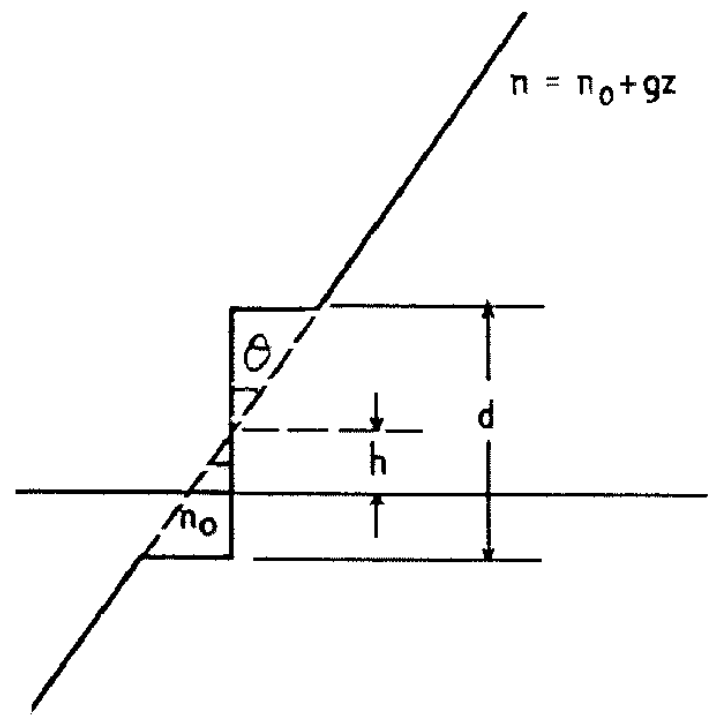

Fig. 10. Sketch of a turbulent layer (Woodman and Rastogi, 1984).

(Fig. 11). They found $K_{\theta} \approx 0.2-0.5 \mathrm{~m}^{2} / \mathrm{s}$, with peak values of $\sim 2 \mathrm{~m}^{2} / \mathrm{s}$,

Note that such an evaluation is an Eulerian one, as it is inferred from the estimated flux at a fixed location, with the turbulent layers being advected through the radar sample volume.

A theoretical Lagrangian approach was recently proposed by Vaneste and Haynes (2000). They modelize the diffusion process as a continuous-time random walk. At random time, a fluid particle encounters a turbulent patch. It is then vertically displaced. The variance of the resulting displacement $\sigma_{z}^{2}$ is related to the local diffusivity (within the turbulent patch):

$K_{\theta}^{\text {Patch }}=\frac{\sigma_{z}^{2}}{2 \tau_{m}}$,

where $\tau_{m}$ is the mean time between successive encounters.

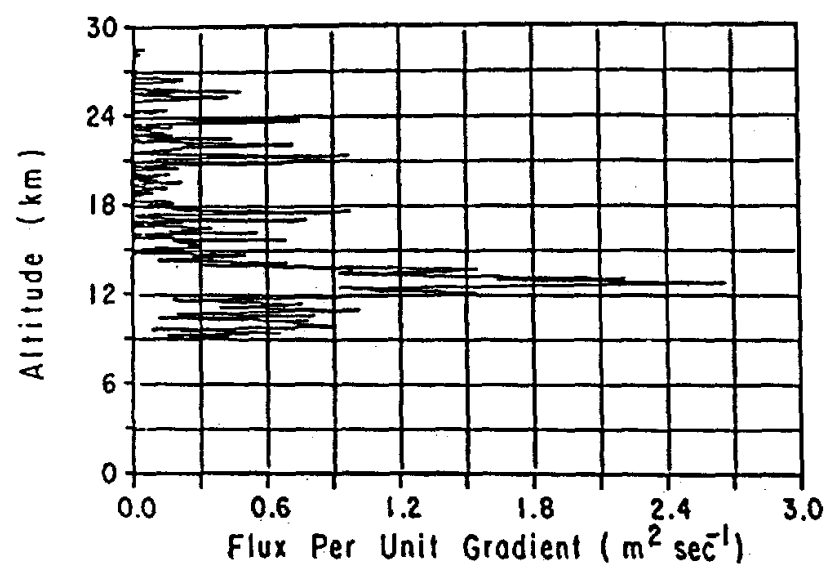

Fig. 11. Flux per unit gradient of a passive scalar. The diffusivity is evaluated by combining the observations of turbulent layers with local diffusivity estimates (Woodman and Rastogi, 1984).

The effective diffusivity depends on three parameters (i.e. on the P.D.F. of these quantities):

$-d$, the thickness of the turbulent layers;

- $\sigma_{z}$, the vertical displacement within a turbulent patch of height $d$ (i.e. turbulence intensity);

- $\tau_{m}$, the waiting time between successive encounters.

In the long time limit, by assuming complete mixing within each patch (that is Dewan's assumption), they obtain (Vaneste and Haynes, 2000):

$K_{\theta}^{e f f}=\frac{\overline{d^{3}}}{12 H \tau_{m}}$,

where $H$ is the height of the considered atmosphere. Using the relation $H \tau_{m}=\bar{d} \tau_{L} / F_{T}$ (Dewan, 1981), Eq. (43) reads:

$K_{\theta}^{e f f}=F_{T} \frac{\overline{d^{3}}}{12 \bar{d} \tau_{L}}$.

In a related work, Alisse et al. (2000b) consider the case of a partial mixing within the patches and proposed an expression for the effective diffusion as a function of the turbulent fraction $F_{T}$, layer thickness $d$ and lifetime $\tau_{L}$ :

$K_{\theta}^{e f f}=F_{T} \frac{\overline{d^{3}}}{12 \overline{d \tau_{L}}}(1-c)$,

where $c$ characterizes the imperfection of mixing resulting from the finite diffusivity and finite lifetime of the patches.

\subsection{An energetics point of view}

Interesting points of view were developed for describing the mixing properties of stratified turbulence through the energy budget. It has been for a long time recognized that mixing, through destratification, results in an increase in the background potential energy (e.g. Thorpe, 1973). The background potential energy (BPE), introduced by Lorenz (1955), 


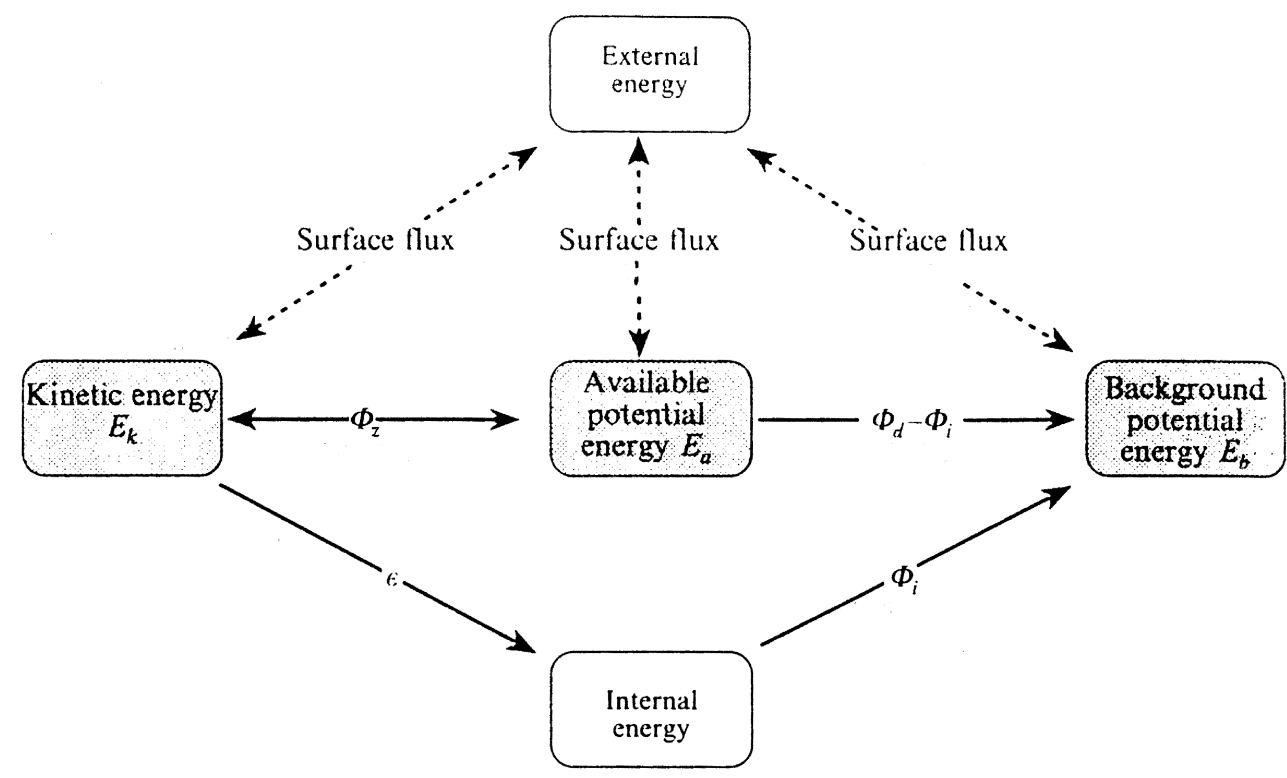

Fig. 12. Energy diagram for density-stratified Boussinesq flow. The energy within a fixed volume can be stored as kinetic, available potential energy, background potential energy, or internal energy (Winters et al., 1995).

is the minimum of the potential energy reachable through adiabatic rearrangement of the fluid parcels. The TPE is defined by reference to that BPE, as the difference between the total gravitational potential energy and that minimum state.

Winters et al. (1995) showed how to relate the mixing properties of turbulence to the energy budget. A fraction of the energy supplied to turbulent motions is converted into TPE (buoyancy flux), an other fraction being irreversibly converted into heat at a rate $\epsilon_{k}$. The TPE is partly irreversibly converted into background potential energy. These authors proposed an expression for the effective diffusivity for an incompressible fluid (i.e. water). Their results cannot be directly used for the atmosphere however (due to the fact that density is not a conservative quantity as for liquid). Nevertheless, such an energy balance sheds a new light on the issue of turbulent mixing. The close relationship between mixing and irreversible energy conversions is formally cleared. Indeed, the dissipation rates (TPE and TKE) express the irreversible conversion of energy into background potential energy and internal energy (i.e. heat) (Fig. 12).

McIntyre (1989) examined the mixing properties of smallscale turbulence through the energy budget of a breaking gravity wave. This author found that the efficiency of mixing might depend on the so-called wave super-saturation (expressing the excess of the wave amplitude relative to the unstability threshold). He further concluded that small-scale turbulence has a negligible impact on vertical transport in the summer polar mesosphere.

\section{Discussion and concluding remarks}

This paper summarizes the inference methods of the mixing due to small-scale turbulence from MST radar measurements. Since the early developments of the MST radar technique (Woodman and Guillen, 1974) considerable progress has been made concerning the physics of measurements (understanding of scattering processes), and data processing methods (inference of turbulence parameters). MST radars measurements allow now for fairly consistent and reliable estimations of the energetic parameters of small-scale turbulence, TKE and $C_{n}^{2}$, even though some assumptions might be questioned (isotropy, homogeneity, stationarity). Also, MST radar measurements have revealed a lot about the morphology of atmospheric turbulence, particularly about the layered structure of turbulent events.

If concerned with the mixing properties of turbulence, however, several difficulties arise. The evaluation of an effective "turbulent diffusivity" is clearly a two-step process. First, the measurements of energetic parameters of smallscale motions allow one to evaluate the local dissipation rates and related local diffusivities, with the term "local" meaning here "within the turbulent patches". Significant progress has been made, and continues to be made, in that direction. Then, because the turbulence is intermittent in space and time, the effective transport is very likely to be dependent on the space and time characteristics of the turbulent events. Indeed, recent theoretical approaches convincingly suggest that the effective diffusivity results from the statistics of both the local properties (i.e. energy dissipation and mixing) but also of the space-and-time distribution of turbulent patches.

Concerning the evaluation of the local diffusivity from radar measurements, several methodological difficulties can be identified. The turbulent diffusivity certainly depends on the local turbulence "intensity" (i.e. TKE or $\epsilon_{k}$ ) but not only:

- The turbulence intensity is usually characterized from the dissipation rate of TKE, $\epsilon_{k}$, that is the rate of 
conversion (per unit mass) of TKE into heat (i.e. into internal energy). Now, the turbulent diffusivity is precisely related to that fraction of turbulent energy that is not dissipated into heat (i.e. $\epsilon_{p}$ rather than $\epsilon_{k}$ ). Consequently, the mixing properties of turbulence are expressed as a function of the ratio of dissipation rates $\gamma=\epsilon_{p} / \epsilon_{k}$. The question of whether the ratio of dissipation rates $\gamma$, or related mixing efficiency $R_{f}$, can reasonably be treated as a constant, or rather evolves during the life cycle of the turbulent events is still an open one.

- The estimation of quantities describing the turbulence energetics, and related diffusivity, depends on local atmospheric conditions, that is on non-measured quantities (intense turbulence in a weakly stratified medium will have a quasi-null impact on mixing). There is a clear need for simultaneous measurements of turbulence quantities and of local atmospheric parameters (especially of the temperature and humidity gradients). In this regard, the new methods combining radar measurements with RASS measurements (Gossard et al., 1998; Tsuda et al., 2001), balloon measurements (Mohan et al., 2001; Wilson and Dalaudier, 2003), or GPS measurements (Gossard et al., 1999) appear very promising.

A key issue is the turbulence intermittency (i.e. the second step). Radar measurements have revealed the striated nature of atmospheric turbulence. Theoretical works showed that the transport induced by intermittent turbulence can be parameterized as an effective diffusivity by taking into account the statistics of turbulent events (local diffusivity, layer depth, lifetime, turbulent fraction). Even though some statistical results exist about the space-time distribution of turbulent events (e.g. Hocking, 1991; Nastrom and Eaton, 2001), there is a clear lack of information about it (to our knowledge). High resolution radar measurements have undoubtedly the capability to provide valuable statistical data about the turbulence morphology. In this regard, new interferometry techniques (e.g. Luce et al., 2002b; Palmer et al., 1998), or FM-CW (Frequency Modulated-Continuous Wave) radars (Eaton, 1995), appear undoubtly as very promising tools.

Our present understanding of small-scale turbulence in the free atmosphere (from the troposphere to the upper mesosphere) relies for a large part on the use of clear air radars. Since they allow one to characterize both the energetics of turbulent events as well as the statistics of the space and time distribution of turbulent patches, MST radar should be an essential tool for the estimation of the actual diffusivity due to small-scale turbulence.

Acknowledgements. The author is indebted to E. M. Dewan and to another reviewer for valuable comments which greatly contributed to improve the paper.

Topical Editor U.-P. Hoppe thanks E. M. Dewan and another referee for their help in evaluating this paper.

\section{References}

Alisse, J.-R. and Sidi, C.: Experimental probability density functions of small-scale fluctuations in the stably stratified atmosphere, J. Fluid. Mech., 402, 137-162, 2000a.

Alisse, J.-R., Haynes, P. H., Vanneste, J., and Sidi, C.: Quantification of turbulent mixing in the lower stratosphere from temperature and velocity microstructure measurements, Geophys. Res. Lett., 27, 2621-2624, 2000b.

Balluch, M. G. and Haynes, P. H.: Quantification of lower stratospheric mixing processes using aircraft data, J. Geophys. Res., 102, 23 487-23 504, 1997.

Barat, J.: Some characteristics of clear air turbulence in the middle stratosphere, J. Atmos. Sci., 39, 2553-2564, 1984.

Barat, J. and Bertin, F.: Simultaneous measurements of temperature and velocity fluctuations within clear air turbulence layers: Analysis of the estimate of dissipation rate by remote sensing techniques, J. Atmos. Sci., 41, 1613-1619, 1984.

Bertin, F., Barat, J., and Wilson, R.: Energy dissipation rates, eddy diffusivity and the Prandtl number: An in situ experimental approach and its consequences on radar estimate of turbulent parameters, Radio Sci., 32, 791-804, 1997.

Briggs, B. H.: Radar observations of atmospheric winds and turbulence: A Comparison of Techniques, J. Atmos. Terr. Phys., 42, 823-833, 1980.

Chu, Y.-H.: Beam Broadening Effect on Oblique MST radar Doppler Spectrum, J. Atmos. Ocean. Tech., 19, 1955-1967, 2002.

Cohn, S. A.: Radar measurements of Turbulent Eddy Dissipation Rate in the Troposphere: A Comparison of Techniques, J. Atmos. Ocean. Tech., 12, 85-95, 1995.

Czechowsky, P., Ruester, R., and Schmidt, G.: Variations of mesopsheric structure in different seasons, Geophys. Res. Letts., 6, 459-462, 1979.

Dalaudier, F., Sidi, C. M. C., and Vernin, J.: Direct evidence of sheets in the atmospheric and temperature field, J. Atmos. Sci., 51, 237-248, 1994.

Dalaudier, F., Luce, H., and Crochet, M.: MUTSI: High resolution balloon measurements and MU radar observations, in: Proc. of the 15th ESA symposium on European Rocket and Balloon Programmes and related research, ESA, SP-471, 127-130, 2001.

Delage, D., Roca, R., Delcourt, J., Crémieu, A., Massebeuf, M., Ney, R., and Velthoven, V.: A consistency check of three radar methods for monitoring eddy diffusion and energy dissipation rates through tropopause, Radio Sci., 32, 757-768, 1997.

Dewan, E. M.: Stratospheric spectra resembling turbulence, Science, 204, 832-835, 1979.

Dewan, E. M.: Estimates of vertical eddy diffusivity due to turbulent layers in the stratosphere, AFGL-TR, 79-0042, 1-30, 1979a.

Dewan, E. M.: Mixing in billow turbulence and stratospheric eddy diffusion, AFGL-TR, 79-0091, 1-32, 1979b.

Dewan, E. M.: Turbulent vertical transport due to thin intermittent mixing layers in the stratosphere and other stable fluids, Science, 211, 1041-1042, 1981.

Dillon, T. M. and Park, M. M.: The available potential energy of overturns as an indicator of mixing in the seasonal thermocline, J. Gephys. Res., 92 (C5), 5345-5353, 1987.

Dole, J. and Wilson, R.: Estimates of turbulent parameters in the lower stratosphere - upper troposphere by radar observations: A novel twist, Geophys. Res. Lett., 27, 2625-2628, 2000.

Dole, J., Wilson, R., Dalaudier, F., and Sidi, C.: Energetics of Small Scale Turbulence in the Lower Stratosphere from High Resolu- 
tion Radar Measurements, Ann. Geophys., 19, 945-952, 2001.

Doviak, R. J. and Zrnić, D. S.: Doppler radar and weather observations, Academic Press, second edn., 1993.

Eaton, F. D.: A new frequency-modulated continuous wave radar for studying planetary boundary layer morphology, Radio Science, 30 (1), 75-88, 1995.

Eaton, F. D. and Nastrom, G. D.: Preliminary estimates of the vertical profiles of inner and outer scales from White Sands Missile Range, New Mexico, VHF radar observation, Radio Science, 33, 895-903, 1998.

Fernando, H. J. S.: Environmental Stratified Flows, chap. Turbulence in Stratified Fluid, Kluwer Academic Publishers, 2002.

Frehlich, E.: Laser scintillation measurements of the temperature spectrum in the atmospheric surface layer, J. Atmos. Sci., 49, 1494-1509, 1992.

Frisch, A. S. and Clifford, S. F.: A study of convection capped by a stable layer using Doppler radar and acoustic echo sounder, J. Atmos. Sci., 31, 1622-1428, 1974.

Fukao, S., Yamanaka, M., Ao, N., Hocking, W. K., Sato, T., Yamamoto, M., Nakamura, T., Tsuda, T., and Kato, S.: Seasonal variability of vertical diffusivity in the middle atmosphere, 1. Three-year observations by the middle and upper atmosphere radar, J. Geophys. Res., 99, 18 973-18 987, 1994.

Gage, K. S.: Evidence for a $k^{-5 / 3}$ law inertial range in mesoscale two-dimensional turbulence, J. Atmos. Sci., 36, 1950-1954, 1979.

Gage, K. S., Green, J. L., and VanZandt, T. E.: Use of Doppler radar for the measurement of atmospheric turbulence parameters from the intensity of clear air echo, Radio Sci., 15, 407-416, 1980.

Gargett, A. E. and Moum, J. N.: Mixing efficiencies in turbulent tidal fronts: results from direct and indirect measurements of density fluxes, J. Phys. Oceanogr., 25, 2583-2608, 1995.

Garrett, C.: Mixing in the ocean interior, Dyn. Atm. Oceans, 3, 239-265, 1979.

Gill, A.: Atmosphere-Ocean Dynamics, Academic Press, 1982.

Gossard, E. E. and Strauch, R. G.: Doppler radar and weather observations, Developments in Atmospheric Science, Elsevier, 1983.

Gossard, E. E., Wolfe, D. E., Moran, K. P., Paulus, R. A., Anderson, K. D., and Rogers, L. T.: Measurements of clear-air gradients and turbulence properties with radar wind profilers, J. Atmos. Ocean. Tech., 15, 321-342, 1998.

Gossard, E. E., Gutman, S., Stankov, B. B., and Wolf, D. E.: Profiles of radio refractive index and humidity derived from radar wind profilers and Global Positioning System, Radio Sci., 34 (2), 371$383,1999$.

Hall, C. M., Hope, U.-P., Blix, T. A., Thrane, E. V., H., M. A., and Meek, C. E.: Seasonal variation of turbulent energy dissipation rates in the polar mesosphere: a comparison of methods, Earth Plannets Space, 51, 515-524, 1999.

Hall, C. M., Nozawa, S., Manson, A. H., and Meek, C. E.: Determination of turbulent energy dissipation rate directly from MFradar determined velocity, Earth Plannets Space, 52, 137-141, 2000.

Hill, R. J.: Spectra of fluctuations in refractivity, temperature, humidity, and the temperature-humidity cospectrum in the inertial and dissipation range, Radio Sci., 13, 953-961, 1978.

Hocking, W. K.: On the extraction of atmospheric turbulence parameter from radar backscatter Doppler spectra - I. Theory, J. Atmos Terr. Phys., 45, 89-102, 1983.

Hocking, W. K.: Measurement of turbulent energy dissipation rates in the middle atmosphere by radar techniques : A review, Radio Sci., 20, 1403-1422, 1985.
Hocking, W. K.: Two years of continuous measurements of turbulence parameters in the upper mesosphere and lower thermosphere made with a 2-MHz radar, J. Gephys. Res., 91, 24752491, 1988.

Hocking, W. K.: The effects of middle atmospheric turbulence on coupling between atmospheric regions, J. Geomag. Geoelectr., 43, suppl., 621-636, 1991.

Hocking, W. K.: An assessment of the capabilities and limitations of radars in measurements of upper atmosphere turbulence, Adv. Space Res., 17 (11), 37-47, 1997.

Hocking, W. K.: The dynamical parameters of turbulence theory as they apply to middle atmosphere studies, Earth Planets Space, 51, 525-541, 1999.

Hocking, W. K. and Mu, K. L.: Upper and middle tropospheric kinetic energy dissipation rates from measurements of $C_{n}^{2}$ - review of theories, in-situ investigations, and experimental studies using the Buckland Park atmospheric radar in Australia, J. Atmos. Sol. Terr. Phys., 59, 1779-1803, 1997.

Hocking, W. K. and Röttger, J.: The structure of turbulence in the middle and lower atmosphere seen by and deduced from MF, HF, and VHF radar, with special emphasis on small-scale features and anysotropy, Ann. Geophys., 19, 933-944, 2001.

Hocking, W. K., Fukao, S., Tsuda, T., Yamamoto, M., Sato, T., and Sato, K.: Aspect sensitivity of stratospheric VHF radio wave scatterers, particularly above $15 \mathrm{~km}$ altitude, Radio Sci., 25, 613627, 1990.

Hooper, D. and Thomas, L.: Aspect sensitivity of VHF scatterers in the troposphere and stratosphere from comparisons of powers in off-vertical beams, J. Atmos. Solar-Terr. Phys., 57, 655-663, 1995.

Ivey, G. and Imberger, J.: On the nature of turbulence in a stratified fluid, Part 1: The energetics of mixing, J. Phys. Oceanogr., 21, 650-658, 1991.

Kennedy, P. J. and Shapiro, M. A.: Further Encounters with Clear Air Turbulence in Research Aircraft, J. Atmos. Sci., 37, 986-993, 1980.

Kurosaki, S., Yamanaka, M. D., Hashiguchi, H., Sato, T., and Fukao, S.: Vertical eddy diffusivity in the lower and middle atmosphere: a climatology based on the MU radar observations during 1986-1992, J. Atmos. Sol. Terr. Phys., 58, 727-734, 1996.

Legras, B., Joseph, B., and Lefèvre, F.: Vertical diffusivity in the lower stratosphere from Lagrangian back-trajectory reconstruction of ozone profiles, J. Geophys. Res., 108(D18), 4562, 2003.

Lilly, D. K., Waco, D. E., and Aldefang, S. I.: Stratospheric mixing estimated from high altitude turbulence measurements, J. Appl. Meteorol., 13, 488-493, 1974.

Lindborg, E.: Can the atmospheric kinetic energy spectrum be explained by two-dimensional turbulence?, J. Fluid. Mech., 388, 259-288, 1999.

Lorenz, E. N.: Available potential energy and the maintenance of the general circulation, Tellus, 7, 157-167, 1955.

Lubken, F.-J.: On the extraction of turbulent parameters from atmospheric density fluctuations, J. Gephys. Res., 97, 20,385-20,395, 1992.

Lubken, F.-J.: Seasonal variation of turbulent energy dissipation rates at high latitudes as determined by insitu measurements of neutral density fluctuations, J. Gephys. Res., 102, 13,44113,456, 1997.

Lubken, F.-J., Hillert, W., Lehmacher, G., and von Zahn, U.: Experiments revealing small impact of turbulence on the energy budget of the mesosphere and lower thermosphere, J. Gephys. Res., 98, 20369-20384, 1993. 
Luce, H., Crochet, M., Dalaudier, F., and Sidi, C.: Interpretation of VHF ST radar vertical echo from in situ temperature sheet observations, Radio Sci., 30, 1002-1025, 1995.

Luce, H., Dalaudier, F., Crochet, M., and Sidi, C.: Direct comparison between in situ and VHF and oblique radar measurements of refractive index spectra: a new successful attempt, Radio Sci., 31, 1487-1500, 1996.

Luce, H., Fukao, S., Dalaudier, F., and Crochet, M.: Strong mixing events observed near the tropopause with the MU radar and hight-resolution Balloon techniques, J. Atmos. Sci., 59, 28852896, 2002a.

Luce, H., Yamamoto, M., Fukao, S., Helal, D., and Crochet, M.: A frequency domain radar interferometric imaging (FII) technique based on high-resolution methods, J. Atmos. Sol. Terr. Phys., 61, 2885-2896, 2002b.

Manson, A. H., Meek, C. E., and Gregory, J. B.: Gravity waves of short period (5-90 min) in the lower thermosphere at $52^{\circ} \mathrm{N}$ (Saskatoon, Canada): 1978/1979, J. Atmos. Terr. Phys., 43, 3544, 1981.

Massie, S. T. and Hunten, D. M.: Stratospheric eddy diffusion coefficients from tracer data, J. Geophys. Res., 86, 9859-9868, 1981.

McEwan, A. D.: Internal mixing in stratified fluids, J. Fluid. Mech., 128, 59-80, 1983.

McIntyre, M. E.: On Dynamics and Transport Near the Polar Mesopause in Summer, J. Gephys. Res., 94 (D12), $14617-$ $14628,1989$.

Mohan, K., Narayama Rao, D., Narayama Rao, T., and Raghavan, S.: Estimation of temperature and humidity from MST radar observation, Ann. Geophys., 19, 855-861, 2001.

Moum, J. N.: Efficiency of mixing in the main thermocline, J. Gephys. Res., 101, 12 057-12 069, 1996.

Nastrom, G. D. and Eaton, F. D.: Tubulence eddy dissipation rates from radar observations at 5-20 km at White Sands Missile Range, New Mexico, J. Geophys. Res, 102, 19495-19505, 1997.

Nastrom, G. D. and Eaton, F. D.: Persistent Layers of Enhanced $C_{n}^{2}$ in the Lower Stratosphere from VHF Radar Observations, Radio Sci., 36, 137-149, 2001.

Nastrom, G. D. and Gage, K. S.: A climatology of atmospheric wavenumber spectra of wind and temperature observed by commercial aircraft, J. Atmos. Sci., 42, 950-960, 1985.

Nastrom, G. D. and Tsuda, T.: Anisotropy of Doppler spectral parmeters in the VHF radar observations at MU and White Sands, Ann. Geophys., 19, 883-888, 2001.

Ogawa, T. and Shimazaki, T.: Diurnal vaaariations of old nitrogen and ionic density in the mesosphere and lower thermosphere: Simultaneous solutions of photochemical-diffusion equations, J. Gephys. Res., 80, 3945-3960, 1975.

Osborn, T. R.: Estimates of the local rate of vertical diffusion from dissipation measurements, J. Phys. Oceanogr., 10, 83-89, 1980.

Osborn, T. R. and Cox, C. S.: Oceanic fine structure, Geophys. Fluid. Dyn., 3, 321-345, 1972.

Ottersten, H.: Radar backscattering from the turbulent clear atmosphere, Radio Sci., 4, 1251-1255, 1969a.

Ottersten, H.: Mean vertical gradient of potential refractive index in turbulent mixing and radar detection of CAT, Radio Sci., 4, 1247-1249, 1969b.

Palmer, R. D., Gopalam, S., Yu, T. Y., and Fukao, S.: Coherent radar imaging using the Capon's method, Radio Sci., 33, 1585-1598, 1998.

Pavelin, E., Whiteway, J., Busen, R., and Hacker, J.: Airborne observations of turbulence, mixing, and gravity waves in the tropopause region, J. Geophys. Res., 107 (D10), 4084, 2002.

Rao, D. N., Ratnam, M. V., Rao, T. N., and Rao, S. V.: Seasonal variation of vertical eddy diffusivity in the troposphere, lower stratosphere and mesosphere over a tropical station, Ann. Geophys., 19, 975-984, 2001.

Rohr, J. J. and Van Atta, C. W.: Mixing efficiency in stably stratified growing turbulence, J. Gephys. Res., 92, 5481-5488, 1987.

Rohr, J. J., Itsweire, E. C., and Van Atta, C. W.: Mixing efficiency in stably stratified decaying turbulence, Geophys. Astrophys. Fluid. Dyn., 29, 221-236, 1984.

Roper, R. G.: Atmospheric turbulence in the meteor region, J. Gephys. Res., 71, 5785-5792, 1966.

Roper, R. G.: On the radar estimation of turbulence parameters in a stably stratified atmosphere, Radio Sci., 35, 999, 2000.

Roper, R. G. and Brosnahan, J. W.: Imaging Doppler Interferometry and the measurement of atmospheric turbulence,, Radio Sci., 32, 1137-1148, 1997.

Satheesan, K. and Murthy, R. F. K.: Turbulence parameters in the tropical troposphere and lower stratosphere, J. Gephys. Res., 107 (D1), ACL 2 (1-13), 2002.

Sato, T. and Woodman, R. F.: Fine Altitude Resolution Observations of Stratospheric Turbulent Layers by the Arecibo $430 \mathrm{MHz}$ Radar, J. Atmos. Sci., 39, 2546-2552, 1982.

Sidi, C. and Dalaudier, F.: Turbulence in the stratified atmosphere: Recent theoretical developments and experimental results, Adv. Space Res, 10 (10), 25-36, 1990.

Smyth, W. D. and Moum, J. N.: Length scales of turbulence in stably stratified turbulence, Phys. Fluids, 12, 1327-1342, 2000.

Smyth, W. D., Moum, J. N., and Caldwell, D. R.: The efficiency of mixing in turbulent patches: Inferences from direct simulations and microstructure observations, J. Phys. Oceanogr., 31, 19691992, 2001.

Tatarskii, V. I.: Wave Propagation in a Turbulent Medium, McGraw-Hill, 1961.

Tatarskii, V. I.: The effects of the turbulent atmosphere on wave propagation, Israel Program for Scientific Translations, Jerusalem, 1971.

Taylor, G. I.: Diffusion by continuous movements, Proc. London Math. Soc., 20, 196-212, 1921.

Tennekes, H. and Lumley, J.: A first course in Turbulence, MIT Press, 1972.

Thorpe, S. A.: Turbulence in stably stratified fluids: a review of laboratory experiments, Bound.-Layer Meteorol., 5, 95-119, 1973.

Tsuda, T., Sato, T., Fukao, S., and Kato, S.: MU radar observations of the aspect sensitivity of backscattered VHF echo power in the troposphere and lower stratosphere, Radio Sci., 21, 971980, 1986.

Tsuda, T., Murayama, Y., Yamamoto, M., Kato, S., and Fukao, S.: Seasonal variation of momentum flux in the mesosphere observed with the MU radar, Geophys. Res. Lett., 17, 725-728, 1990.

Tsuda, T., VanZandt, T. E., and Saito, H.: Zenith-angle dependence of VHF specular reflection echoes in the lower atmosphere, J. Atmos. Solar-Terr. Phys., 59, 761-775, 1997a.

Tsuda, T., Miyamoto, M., and Furumoto, J.: Estimation of a Humidity Profile Using Turbulence Echo Characteristics, J. Atmos. Ocean. Tech., 18, 1214-1222, 2001.

Vaneste, J. and Haynes, P. H.: Intermittent mixing in strongly stratified fluids as a random walk, J. Fluid. Mech., 411, 165-185, 2000.

VanZandt, T. E.: A universal spectrum of buoyancy waves in the atmosphere, Geophys. Res. Lett., 9, 575-578, 1982. 
VanZandt, T. E., Green, J. L., Gage, K. S., and Clarck, W. L.: Vertical profiles of refractivity turbulence structure constant: comparison of observations by the Sunset radar with a new theoretical model, Radio Sci., 13, 819-829, 1978.

VanZandt, T. E., Clarck, W. L., Gage, K. S., Williams, C. R., and Ecklund, W. L.: A dual-wavelength radar technique for measuring the turbulent energy dissipation rate $\epsilon$, Geophys. Res. Lett., 27, 2537-2540, 2000.

VanZandt, T. E., Nastrom, G. D., Furumoto, J., Tsuda, T., and Clarck, W. L.: A dual-beamwidth radar method for measuring atmospheric turbulent kinetic energy, Geophys. Res. Lett., 29 (12), 1572-1575, 2002.

Watkins, B. J., Philbrick, C. R., and Balsley, B. B.: Turbulence Energy Dissipation Rates and Inner Scale Sizes from Rocket and Radar Data, J. Gephys. Res., 93 (D6), 17 009-17 014, 1988.

Waugh, D., Plumb, R. A., Elkins, J. W., et al.: Mixing on polar vortex air into middle latitudes as revealed by tracer-tracer scatter plots, J. Geophys. Res., 102, 13 119-13 134, 1997.

Weinstock, J.: On the theory of turbulence in the buyoancy subrange of stably stratified flows, J. Atmos. Sci., 35, 634-649, 1978.

Weinstock, J.: Using radar to estimate dissipation rate in thin layer of turbulence, Radio Sci., 16, 1401-1406, 1981.

Weinstock, J.: Vertical diffusivity and overturning length in stably stratified turbulence, J. Gephys. Res., 97, 12,653-12,658, 1992.
Wilson, R. and Dalaudier, F.: Simultaneous observations of atmospheric turbulence in the lower stratosphere from balloon soundings and ST radar measurements, in: Proc. of the 10th MST radar workshop, 2003.

Winters, K. B., Lombard, P. N., Riley, J. J., and d'Assaro, E. A.: Available potential energy and mixing in density stratified fluid, J. Fluid. Mech., 289, 115-128, 1995.

Woodman, R. F. and Guillen, A.: Radar observations of winds and turbulence in the stratosphere and mesosphere, J. Atmos. Sci., 31, 493-505, 1974.

Woodman, R. F. and Rastogi, P. K.: Evaluation of effective eddy diffusive coefficients using radar observations of turbulence in the stratosphere, Geophys. Res. Lett., 11, 243-246, 1984.

Worthington, R. M. and Thomas, P. K.: Long-period unstable gravity-waves and associated VHF radar echoes, Ann. Geophys., 15, 813-822, 1997.

Worthington, R. M., Palmer, R. D., and Fukao, S.: An Investigation of Tilted Aspect-Sensitive Scatterers in the Lower Atmosphere, Using the MU and Aberystwyth VHF Radars, Radio Sci., 34, 413-426, 1999a.

Worthington, R. M., Palmer, R. D., and Fukao, S.: Complete maps of the aspect sensitivity of VHF atmospheric radar echoes, Ann. Geophys., 17, 1116-1119, 1999b. 